\title{
Nanolipodendrosome-loaded glatiramer acetate and myogenic differentiation I as augmentation therapeutic strategy approaches in muscular dystrophy
}

\author{
This article was published in the following Dove Press journal: \\ International Journal of Nanomedicine \\ 7 August 2013 \\ Number of times this article has been viewed
}

\section{Ehsan Afzal' \\ Saba Zakeri \\ Peyman Keyhanvar ${ }^{2}$ \\ Meisam Bagheri ${ }^{3,4}$ \\ Parvin Mahjoubi ${ }^{5}$ \\ Mahtab Asadian ${ }^{5}$ \\ Nogol Omoomi ${ }^{5}$ \\ Mohammad Dehqanian ${ }^{6}$ \\ Negar Ghalandarlaki' \\ Tahmineh Darvishmohammadi \\ Fatemeh Farjadian ${ }^{7}$ \\ Mohammad Sadegh Golvajoee' \\ Shadi Afzal ${ }^{8}$ \\ Maryam Ghaffari ${ }^{9}$ \\ Reza Ahangari Cohan ${ }^{10}$ \\ Amin Gravand"' \\ Mehdi Shafiee Ardestani ${ }^{12,13}$ \\ 'Department of Biology, Science and Research Branch, Islamic Azad University, ${ }^{2}$ School of \\ Advanced Technologies in Medicine, Tehran \\ University of Medical Sciences, Tehran, Iran; \\ ${ }^{3}$ Department of Molecular Reproduction, \\ Development and Genetics, Indian Institute of \\ Science, Bangalore, India; ${ }^{4}$ Autoimmune Disease \\ Research Center, Shiraz University of Medical \\ Sciences, Shiraz, ${ }^{5}$ National Cell Bank, Pasteur \\ Institute of Iran, ${ }^{6}$ Department of Nanotechnology, \\ Faculty of Advanced Sciences and Technologies, \\ Pharmaceutical Sciences Branch, Islamic Azad \\ University, Tehran, ${ }^{7}$ Department of Chemistry \\ College of Science, Shiraz University, Shiraz, \\ ${ }^{8}$ Department of English, Beyza Branch, Islamic \\ Azad University, Beyza, 'Department of Basic \\ Science at Apadana Education Institute, Shiraz, \\ ${ }^{10}$ Department of Virology, Pasteur Institute \\ of Iran, Tehran, "Faculty of Pharmacy, Ahwaz \\ Jondishapour University of Medical Sciences, \\ Ahwaz, ${ }^{2}$ Department of Medicinal Chemistry \\ and Radiopharmacy, Faculty of Pharmacy, Tehran \\ University of Medical Sciences, ${ }^{13}$ Department \\ of Radiopharmacy, Faculty of Pharmacy, Tehran \\ University of Medical Sciences, Tehran, Iran}

Correspondence: Mehdi Shafiee Ardestan

Department of Radiopharmacy,

Faculty of Pharmacy,

Tehran University of Medical Sciences,

Tehran I4I76I44II, Iran

Fax/Tel +9821669533II

Email shafieeardestani@gmail.com
Backgrond: Muscular dystrophies consist of a number of juvenile and adult forms of complex disorders which generally cause weakness or efficiency defects affecting skeletal muscles or, in some kinds, other types of tissues in all parts of the body are vastly affected. In previous studies, it was observed that along with muscular dystrophy, immune inflammation was caused by inflammatory cells invasion - like $\mathrm{T}$ lymphocyte markers (CD8+/CD4+). Inflammatory processes play a major part in muscular fibrosis in muscular dystrophy patients. Additionally, a significant decrease in amounts of two myogenic recovery factors (myogenic differentation 1 [MyoD] and myogenin) in animal models was observed. The drug glatiramer acetate causes anti-inflammatory cytokines to increase and T helper (Th) cells to induce, in an as yet unknown mechanism. MyoD recovery activity in muscular cells justifies using it alongside this drug.

Methods: In this study, a nanolipodendrosome carrier as a drug delivery system was designed. The purpose of the system was to maximize the delivery and efficiency of the two drug factors, MyoD and myogenin, and introduce them as novel therapeutic agents in muscular dystrophy phenotypic mice. The generation of new muscular cells was analyzed in SW1 mice. Then, immune system changes and probable side effects after injecting the nanodrug formulations were investigated.

Results: The loaded lipodendrimer nanocarrier with the candidate drug, in comparison with the nandrolone control drug, caused a significant increase in muscular mass, a reduction in CD4+/CD8+ inflammation markers, and no significant toxicity was observed. The results support the hypothesis that the nanolipodendrimer containing the two candidate drugs will probably be an efficient means to ameliorate muscular degeneration, and warrants further investigation.

Keywords: muscular dystrophy, glatiramer acetate, MyoD factor, drug delivery

\section{Introduction}

Neuromuscular diseases are a group of heterogeneous hereditary diseases in which motor units are impaired. ${ }^{1-5}$ These diseases can be categorized into four groups; one of them is called myopathy. Myopathies are muscular diseases causing pain and reducing muscular efficiency. ${ }^{5-11}$ Muscular dystrophy (MD) as a myopathy relates to progressive (gradual) muscular weakness, degeneration and generation of muscular fibers, and probable substitution of muscular fibers for connective and adipose tissues, without nervous system interference. ${ }^{10-14}$

Significant decrease in muscle proteins and cells, and muscular tissues death are clear characteristics of this disease. Most clinical symptoms occur in skeletal muscles. Heart and diaphragm muscles are also often involved, as most patients die from heart 
and respiratory failure..$^{3-8}$ Generally, the pathology of skeletal muscles in MD patients shows the substitution of fibrosis and adipose tissues in muscle. Histopathology analysis shows the changes in dystrophic muscles including muscle fiber necrosis, fibrosis, and regeneration. ${ }^{3-6}$

Beside MD, inflammatory cell invasion including macrophages, T-cells, CD4+, CD8+, and sometimes eosinophils are also observed. Inflammatory processes play an important role in increasing muscular damage and muscle fibrosis in MD. Inflammation, along with muscular degeneration, causes intensification of the muscle pathobiology state by destroying the remaining tissue and preparing it to rebuild. ${ }^{1-3,15-27}$ For instance, in an mdx mice model of Duchenne MD (DMD), T-cells had a major part in skeletal muscle fibrogenesis and death. ${ }^{17-21}$ Additionally, two fibrosis markers - fibronectin and vimentin - had a significant increase in comparison with normal models among patients suffering from DMD compared with healthy humans. On the contrary, recovery factors of MyoD and Myogenin reduced in value. ${ }^{17-27}$

Myogenic differentiation 1 (MyoD) is a key protein regulating muscular differentiation. MyoD expression is necessary as one of the primary myogenic regulatory factors in transforming satellite cells into myoblasts.

Nowadays, one of the main treatments for MD is using glucocorticoid drugs, oligonucleotide mediated exon splicing, and viral mediated (eg, adeno-associated virus) gene therapy/augmentation approaches. So far, the mechanism of the drug effect, the age of the patient to be treated, and its optimal period have not been determined. . $11,24,27-34^{-}$

Glatiramer acetate (GA), a synthetic drug with an average molecular mass of $6.4 \mathrm{KD}$ and available on the market as Copaxone ${ }^{\circledR}$ (Teva Pharmaceuticals, Petah Tikva, Israel), is used to treat multiple sclerosis (MS). This drug is a peptide combined with four amino acids (L-Alanin, L-Lysine, L-Glutamic acid, and L-Tyrosine) which reduces the progression of MS and the disability caused by it and its recurrence. ${ }^{3}$

GA was first designed for simulating myelin-based protein, but then it was realized it would be effective in modifying the immune system by activating and inducing peripheral T-cell suppressors. The mechanism of GA's effect is not yet known, but it seems it suppresses proinflammatory cytokines' expression, increases anti-inflammatory cytokines, and induces $\mathrm{T}$ helper $(\mathrm{Th}) 2$ cells by changing immune systems from Th1 to Th2.

Based on nanomedical science and drug delivery, the use of certain nanoparticle carriers - like liposomes and dendrimers - in co-delivering a novel drug regimen can be effective in causing improved delivery and increased drug effectiveness. These drugs are able to target the damaged microenvironment in tissue, depending on transfer and the required dose, and prevent side effects and not cause allergies. ${ }^{1-8,34,35,37-41}$

Among the carriers used in drug delivery, micelles, liposomes, nanoparticles, dendrosomes, liquid crystals, hydogels, cubosomes, and hexosomes are commonly used. Two subcategories of nanostructures, playing important roles in drug delivery science, are liposomes and dendrimers. Liposomes are a group of nano lipids formed like a hollow lipid nanosphere, while dendrimers are thin, branched, and symmetrical macromolecules that consist of a central core, tree-like branched units, and some functional groups. ${ }^{5,15,22,41}$

Because of the similarity between a two-layer liposomal membrane and cellular two-layer membrane, liposomes are commonly used as artificial tissue. ${ }^{18,22}$ Liposomes in drug delivery have some special characteristics. For instance, liposomes can target a drug to a specific position in the body, which increases treatment efficiency (direction). In addition, liposomes can act as a store which releases the drug gradually. This maintains the concentration of the drug as long as possible and also increases the effect length. Additionally, liposomes can release the drug as a source within the cells after aggregation in macrophages (sustained release).

Due to the membranous boundary of the liposome wall, the drugs coupled with the membrane or those surrounded in the liquid phase within the liposome, are protected against harmful factors like degradable enzymes and the patient is immune to the harmful toxic effects of the drugs.

In addition, liposomes can interact with target cells in different ways. For instance, they can stimulate endocytosis, which aids the drug in entering the desired cells (DNA) when otherwise it would not be able to. Among the other characteristics of this nanoparticle are controlled release and amplification. ${ }^{18,20,22,25}$

The efficiency of the drug delivery can be increased by connecting other nanocarriers to the liposomes. Nanolipodendrosome is a type of dendritic family formed by connecting dendritic nanoparticles to liposomes. These nanoparticles are used on liposomes for various reasons. ${ }^{12}$ Although liposomes have been extensively studied as a promising drug delivery model for bioactive compounds, there still remains major drawbacks for widespread pharmaceutical application. One of the approaches for overcoming the factors related to the suboptimal efficacy of liposomes in drug delivery entails modifying the liposome surface with functional moieties.

Liposomes by themselves are not functional for drug delivery; they are only carriers (vehicles) ${ }^{26}$ with the addition 
of other nanoparticles such as polyethylene glycol (PEG) and polyethyleneimine (PEI). These other nanoparticles are necessary in order to modulate the liposomes' surface, create stability in the liposomes' lipid structures against enzymatic effects and $\mathrm{pH}$ changes, and increase both the contact surface and absorbtion into the cells of the liposomes. On the other hand, linking antibodies on the liposomes' surface directly or indirectly (by linking them to nanoparticles such as nanopolymers that are linked to the liposomes' surface) provides targeted drug delivery, which in some cases is achieved by using the antibody against the tumor cell's antigen which directs the nanocarrier toward the tumor cells. ${ }^{8,32}$ Polymerized liposomal nanoparticles (PLNs) have the potential to be conjugated to a tumor targeting agent in hopes of delivering a cytotoxic payload directly to the cancer cells, thus minimizing systemic toxicity. ${ }^{27}$

Generally, using nanoparticles causes the membrane of liposomes loaded with drug to be stable. Therefore, the usage of this carrier is very effective in drug direction, protection, internalization, targeting, and amplification. This compound has less in vivo toxicity and higher stability and efficiency than other traditionally used drug delivery systems. ${ }^{12,40}$

Global statistics show that almost one in every 3000 people in the world is suffering from MD. On the other hand, there has been no effective treatment for any type of dystrophy so far. Also, most treatments are effective only in the early stages of the disease. Among available drugs for this disease, only oral corticosteroids (prednisone) may lead to partial improvement in muscles, but only for about 3 years. Since prednisone is a corticosteroid, it has many side effects such as osteoporosis, eye problems, and memory disorders. ${ }^{34}$ Recently, genetic researchers have been trying to find gene therapy and exon skipping methods to treat this disease, but the effect of these methods has not been proved yet. ${ }^{11,16,24,34}$

Previous studies on this subject have documented the effectiveness of GA as a modulator of the immune system in MS. ${ }^{9-11,27-29}$ According to the currently available data, GA displays a wide range of anti-inflammatory activities: immune modulation induced by Th2 cells and an increase in anti-inflammatory cytokines. ${ }^{9,29}$ Also, using GA in parallel to the MyoD factor that plays a role in the determination and induction of satellite cells to myoblasts, muscular proliferation/differentiation has been improved. ${ }^{23,35}$ In this study, we attempted to use nanomedicine-based technologies to insert these two drugs into a nanolipodendrosome carrier and synthesize a new compound with higher effectiveness and less side effects against MD applied treatments, which may be effective even in advanced stages of the disease.

\section{Methods}

\section{Materials}

All materials (including the chemical and biological compounds used for liposome preparation or cell culture medium) were provided by Sigma-Aldrich (St Louis, MO, USA) and all the solvents (including methanol, chloroform, dimethylformamide, and dimethyl sulfoxide) were provided by Merck $\mathrm{KGaA}$ (Darmstadt, Germany) and used for the experiments without any further purification. MyoD was gifted from the Laboratory of Physiological experiments led by Professor Moghaddam. G2-anionic linear globular dendrimer nanoparticles were obtained from Namazi's laboratory at the Faculty of Chemistry, Tabriz University, Iran. ${ }^{6}$

\section{Animals}

SW-1 mice were selected for the experiments and were divided into three general groups $(\mathrm{A}=$ control, $\mathrm{B}=$ receiving nandrolone, and $\mathrm{C}=$ liposome-dendrimer-drug loaded), and each general group was divided into subgroups each containing 10 animals. Each group was kept separately, and the animals were maintained in a conventional animal room at the Pasteur Institute of Iran, which was air-conditioned $\left(21^{\circ} \mathrm{C}-22^{\circ} \mathrm{C}\right.$ and $60 \%-70 \%$ relative humidity) and ventilated 16 times/ hour, and they were provided with an adequate diet and tap water ad libitum. The animal experiments were carried out in accordance with the recommendations of the Declaration of Helsinki and the internationally accepted principles for use of experimental animals, and the animal experiments were also confirmed by the local ethics committee of our institution.

\section{Liposome synthesis}

In this study, liposomes were synthesized through the dehydration-rehydration vesicule (DRV) method. The liposome was of unilamellar vesicular type (ULV). It contained 7:2:1 (mmol) cholesterol:phosphotidylcholine (PC):dimethyl dioctadecyl ammonium bromide (DDAB). ${ }^{4,21}$ In this method, the required amount of phospholipids and cholesterol were dissolved using chloroform and ether organic solvent. The solvent was evaporated in a rotary evaporator (Heidolph; Schwabach, Germany) in order to create a thin lipid film on the balloon's wall. Five milliliters of distilled water was added to the obtained lipid film at a temperature above the melting temperature (Tm). After vortexing, the empty primary monolamellar vesicule (MLV) liposomes were formed. The obtained MLV liposomes were transformed into small unilamellar vesicles (SUVs) using a bath sonicator (Bioruptor, Diagenode Inc, Denville, NJ, USA). Then a certain amount of stabilizer (vitamin C) was added to the empty SUV and the mixture was quickly frozen 
by nitrogen gas. Finally, it was converted into dry powder by a freeze drying machine (Cuddon; Blenheim, New Zealand).

\section{Connecting dendrimer to the liposome surface}

Next, $10 \mathrm{~mL}$ liposome, $5 \mathrm{mg}$ dendrimer, $10 \mathrm{mg}$ adipic acid dihydrazide (ADH), $10 \mathrm{mg}$ N-ethyl-N-(3-dimethylamine propyl) carboamide (EDC), and $10 \mathrm{mg}$ N-hydroxy-sulfosuccinimide (N-Sulf-HS) were used in order to bind the dendrimer to the liposomes. The reaction was of esterification type. There were carboxylic functional groups at the end of the dendrimer branches. These carboxyl groups will bind to the alcohol groups available in liposomes. The esterification reaction rate is too slow, such that if no catalyst is used in the reaction, its balancing may take several weeks. And due to the fact that the reaction is sensitive to $\mathrm{pH}$ changes, it is not stable in cancerous cells in the body (acidic pH).${ }^{14} \mathrm{In}$ addition, the presence of bulky groups near the reaction (whether acid or alcohol) will slow down the esterification. Thus, ADH was used as a linker. So, an amidation nucleophilic substitution type 2 (SN2) reaction was conducted in which water is a byproduct. The amide bond is resistant to $\mathrm{pH}$ changes, so the problem of instability of this compound in body cells will be solved. Also, there will be no steric hindrance problem.

The yield of this reaction is not very high $(50 \%-60 \%)$ and it is sensitive to the presence of water (water acts as a competitor). Thus, the N-Sulf-HS was used as a water sensitivity reducer. ${ }^{13}$ Additionally, EDC was used as the catalyst (activator of the carboxyl groups). The $\mathrm{pH}$ of the testing environment was 7.2 to 7.3 and the time required for the reaction was 1 day.

Reaction procedures included pouring normal saline and dimethyl sulfoxide (DMSO) solution into a container and then putting it on the magnetic mixer machine with a magnet in it. Afterwards, $10 \mathrm{~mL}$ of synthetic liposome, dissolved in phosphate-buffered saline (PBS), was added to the solution. Then the EDC and N-Sulf-HS were added simultaneously. They were incubated for 5 minutes. The next step was adding ADH. Finally, $5 \mathrm{mg}$ dendrimer powder was added to the total solution and it was incubated for 1 day. The two steps of the reaction are shown in Figure 1.

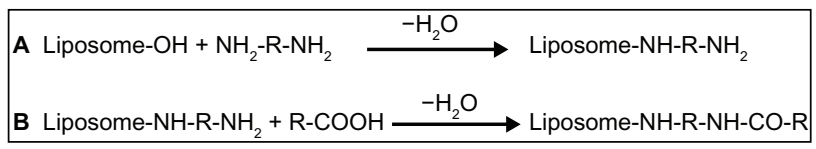

Figure I The reaction of AHD with the liposome hydroxyl group (A) and the reaction of the $A D H$ amino group with the dendrimer carboxyl group (B). Abbreviation: $\mathrm{ADH}$, adipic acid dihydrazide.

\section{Separation and purification using gel-filtration chromatography and thin layer chromatography (TLC)}

Next, $0.5 \mathrm{~g}$ of G75 (fine) sephadex (Sigma-Aldrich) was dissolved in $15 \mathrm{~mL}$ double distilled water and incubated for 1 day in order to create the gel. In gel-filtration chromatography, each of the 20 drops $(1 \mathrm{~mL}$ ) of the fluid, removed from the chromatography column, was collected in a separate tube. To trace the final product, the individual tubes were exposed to TLC.

In this technique, Silica gel sheets (60F254) were considered as the stationary phase (Merck). Non-conjugated liposomes and pure dendrimer were used as the standards. The chloroform and methanol mixture in the volumetric ratio of $3 \mathrm{~mL}$ and $7 \mathrm{~mL}$, respectively, were used as the unknown spot solvent. Chromatography was performed for about $22-25$ minutes at $25^{\circ} \mathrm{C}-26^{\circ} \mathrm{C}$. Finally, after purifying the synthetic nanolipodendritic mixture, it was immediately frozen using nitrogen gas and transformed into powder by a freeze drying machine (Cuddon).

\section{Loading nanolipodenderimer with GA and MyoD protein factor}

Next, $4 \mathrm{mg}$ of synthetic nanolipodenderimer was mixed with $12 \mathrm{~mL}$ of normal saline solution and put on a magnetic mixer machine with a magnet in it. Then, $240 \mu \mathrm{g}$ of GA with $240 \mu \mathrm{g}$ MyoD protein factor in the ratio of $1: 1$ and $6 \mathrm{~mL}$ normal saline were mixed and incubated for 5 minutes. Finally, the mixture was added drop by drop at 30 minute intervals to a synthetic nanolipodendrosome container, which was spinning in the machine, and then incubated for 1 hour. All the procedures mentioned above were carried out at room temperature and TLC techniques were used in order to obtain the best dose of the drug loading. Maximum optimized loaded of each active ingredient onto the dendrimer-liposome was set by TLC and an ultraviolet standard curve from each material at $280 \mathrm{~nm}$. In fact, $240 \mu \mathrm{g}$ of GA with $240 \mu \mathrm{g}$ MyoD protein concurrently was found to be the maximum drug loading amount for the $4 \mathrm{mg}$ nanosized construct (loading efficacy $12 \%, \mathrm{n}=3$ ).

\section{Separation and purification using a $10 \mathrm{kDa}$ dialysis bag}

To purify the loaded nanolipodendrimer with drugs from other pharmaceutical particles, the compound was placed into a $10 \mathrm{kDa}$ dialysis bag (Sigma-Aldrich) and then put in a container containing $2 \mathrm{~L}$ of distilled water for 24 hours on the stirrer. Finally, after purification it was dried using the freeze dryer. 


\section{Size and charge determination}

The size and charge of the loaded and unloaded nanolipodendrosome, liposomal particles, and non-conjugated dendrimer were determined using a Zetasizer machine (Nano ZS; Malvern Instruments, Malvern, UK), which had the measurement size range of $6 \mathrm{~nm}$ to $0.6 \mu \mathrm{m}$, zeta potential measurement range of $-120 \mathrm{mV}$ to $120 \mathrm{mV}$, and molecular weight measurement range of $2 \times 10^{7}$ Daltons to $10 \times 10^{7}$ Daltons.

\section{Microscopic studies}

A transmission electron microscope equipped with an Energy-dispersive X-ray (EDX) spectrometer (EM 900; Carl Zeiss Meditec AG, Jena, Germany) was used in order to determine the size and structure of the liposome and nanolipodendrimer, before and after loading the drugs. A negative staining technique was used to stain the samples with phosphotungstic acid. Then, $30 \mu \mathrm{L}$ of the suspension sample was poured in 300 mesh $\mathrm{Cu}$ grids, which were covered with a thin holey carbon film. After incubation, $10 \mu \mathrm{L}$ of the staining material, $2 \%$ phosphotungstic acid prepared with phosphate buffer $(\mathrm{pH}=6.9)$, was added and incubated for 10 minutes at room temperature. The prepared sample was observed using transmission electron microscopy with the specifications mentioned before.

\section{Animal model}

In this study, $50 \mathrm{SW}-1$ male mice with an average weight of $20 \pm 0.20 \mathrm{~g}$, aged between 4-5 weeks were randomized into five groups. They were kept in conditions of 12 hours of brightness and 12 hours of darkness with full access to food and sufficient water. The first group was called the solvent receiver group (it will be referred to as 1 from now on). No drug was injected into the mice in this group, only the solvent was used in the synthesis of the drugs (saline $0.9 \%$ ). The second group was named the control (it will be referred to as 2 from now on). No injection was performed on the mice in this group. They were kept in the same environmental condition as the other mice. The third group was the nandrolone decanoate receiver group (it will be referred to as 3 from now on). One milliliter of nandrolone decanoate was injected into the mice in this group. The $1 \times(200$ $\mu \mathrm{g} / \mathrm{kg})$ and $2 \times(400 \mu \mathrm{g} / \mathrm{kg})$ doses of the synthetic nanodrug candidate (nanolipodendrosome containing GA and MyoD) were injected into the mice in the fourth and the fifth group, respectively. They were injected into muscle (IM), in biceps femoris muscles on both sides, and this was done twice at 2 -week intervals (one boost). The mice were kept in similar conditions for another 2 weeks.

\section{Magnetic resonance imaging (MRI) studies}

To assess the changes in muscle volume and mass, one mouse was picked from each of three groups (1,3, and 5) and MRI of their skeletal muscles was performed using a 1.5 Tesla MRI machine (GE, Fairfield, CT, USA).

\section{Pathobiology assessment and evaluation}

Onemouse was picked from each of three groups (1,3, and 5) and their muscles were assessed pathobiologically. The study was carried out after cutting and staining in histological slides, with hematoxylin and eosin (H\&E), with $40 \times$ magnification optical microscopy.

\section{Evaluation of the immune system using flow cytometer}

Immune system assessment was performed on the blood samples of three mice picked from group 1, 3, and 5. In this experiment, the concentrations of two $\mathrm{CD}$ markers were determined by flow cytometer via the CD4+/CD8+ protocol $^{36}$ used for the same measurement in patients with AIDS. The ratio of $\mathrm{CD} 4+/ \mathrm{CD} 8+$ was measured in treated groups and divided into $\mathrm{CD} 4+/ \mathrm{CD} 8+$ ratio of the control groups in order to make precise calculations. Finally the result was illustrated by percentage of enhancement or decrease.

\section{Evaluating the physical characteristics of the mice}

First of all, the conjugated toxicity of the synthetic combinations of 30 mice related to groups 1, 3, 4, and 5 was assessed. The type of measured toxicity was acute toxicology. The toxicity test was carried out as follows, according to our institutional ethical committee guidelines:

1. International Committee for Harmonization of Biological compounds (ICHBC)

2. Committee of Proprietors of Medicinal Products (CPMP) Finally, the statistical comparison of the weight of the mice was performed on days 1, 4, and 28 .

\section{Results and discussion Purification of the synthetic compound using gel filtration chromatography and TLC}

As mentioned earlier, in gel filtration chromatography, every 20 drops $(1 \mathrm{~mL})$ of the output fluid removed from the column was collected in a separate tube, and to trace the final product it was exposed to TLC. Sixteen spots, including two standard spots and 14 unknown ones were put on TLC and 
their refraction index (RF index) was measured. This index is calculated by dividing the distance that the unknown spots cover by the distance that the solvent covers. Table 1 shows the RF index of these 16 spots.

The first three tubes showed no spot growth. In fact, there were no spots in the $3 \mathrm{~mL}$ output mixture of the chromatography columns (the first three tubes) indicating the presence of the initial compound or our product. The grown spots in the fourth, fifth, and sixth tubes (with RF index of 0.72 ) were visible obviously at an equal distance. The conjugated nanolipodendrimer compound covered less distance than the dendrimer spot due to the high molecular weight of its two basic compounds: the low liposome interactions with the mobile phase and low solubility. These synthetic nanolipodendritic compounds left the column earlier because they had a bigger size than the rest of the non-conjugated dendritic and liposomal particles. Comparing the RF value of tube 9 and the value of the liposome standard, they had the same RF value, so it could be concluded that there was some non-conjugated dendrimer from the initial reaction in tube 13 , which covered more distance due to its high solubility with the solvent and its low molecular weight.

\section{Size and charge determination of the} loaded and unloaded nanolipodendrosome, liposomal particles, and non-conjugated dendrimer using the Zetasizer machine

The diagrams related to the sizes and charges of the nanoparticles are shown in Figures 2-5. The results of the

Table I The obtained refraction index of the 16 spots

\begin{tabular}{lll}
\hline & Retention time & Mode of detection \\
\hline Component & & \\
Tube I & 0.00 & Undetected spot \\
Tube 2 & 0.00 & Undetected spot \\
Tube 3 & 0.00 & Undetected spot \\
Tube 4 & 0.72 & Detected spot \\
Tube 5 & 0.72 & Detected spot \\
Tube 6 & 0.72 & Detected spot \\
Tube 7 & 0.00 & Undetected spot \\
Tube 8 & 0.00 & Undetected spot \\
Tube 9 & 0.55 & Detected spot \\
Tube I0 & 0.00 & Undetected spot \\
Tube II & 0.00 & Undetected spot \\
Tube I2 & 0.00 & Undetected spot \\
Tube 13 & 0.91 & Detected spot \\
Tube 14 & 0.00 & Undetected spot \\
Standard & & \\
Liposome & 0.55 & Detected spot \\
Dendrimer & 0.91 & Detected spot \\
\hline
\end{tabular}
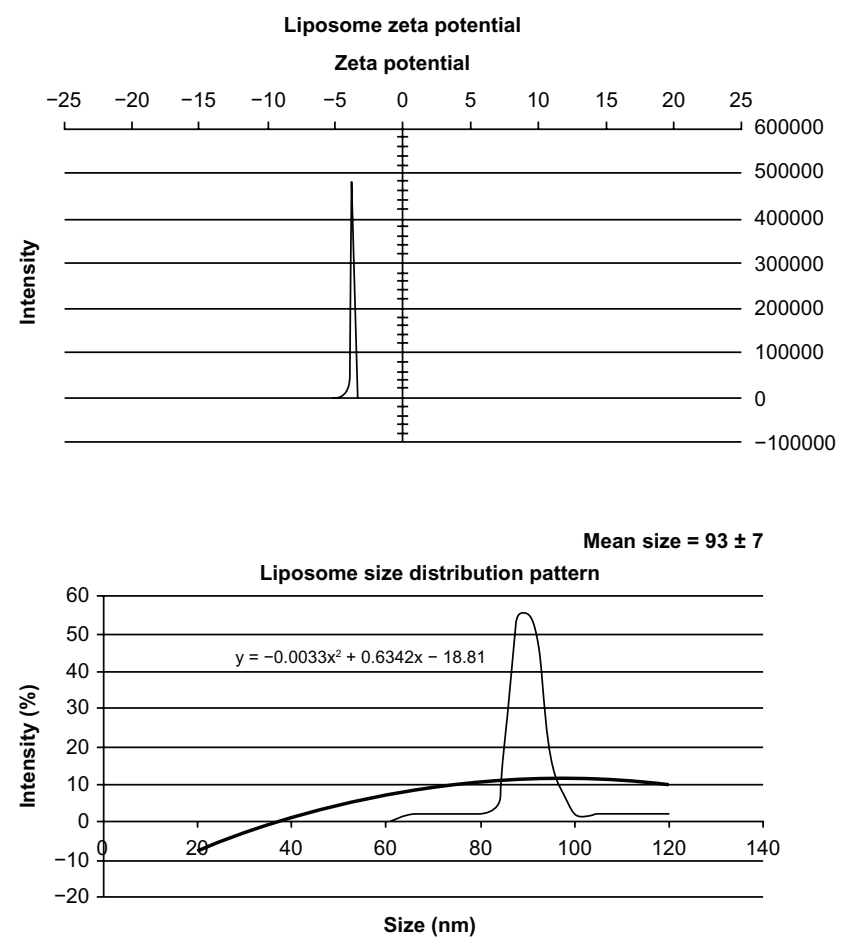

Figure $\mathbf{2}$ The obtained diagram for the size and charge determination of the nonconjugated liposomes using the Zetasizer.

samples analysis as mean \pm standard deviation are shown in Table 2.

\section{Size and structure determination of liposome and nanolipodendrosome, before and after the drug loading using transmission electron microscopy}

In microscope images taken from conjugated liposomes with dendrimer before drug loading (Figure 6), the liposomal spheres are covered by dark halos. These dark halos are formed by phosphotungstic acid (PTA) color penetration and accumulation inside the dendrimer splits, which are conjugated around the liposomes.

In Figure 7, which is taken from the suspension containing nanolipodendrosome particles after drug loading, spheres covered with dark layers can be observed. In this image, large numbers of nanolipodendrosome particles are visible. Some liposomal spheres are relatively transparent and can be seen without the halo. This may be due to a lack of binding or enough binding of liposomes to dendrimer (Figure 7A). After magnifying and focusing on one nanolipodendrosome particle which had a dark halo (Figure 7B), its components were studied using the EDX spectrometer (Figure 7C).

Figure 7D was obtained from the center of the lipodendrosome particle. The presence of the carbon, nitrogen, 

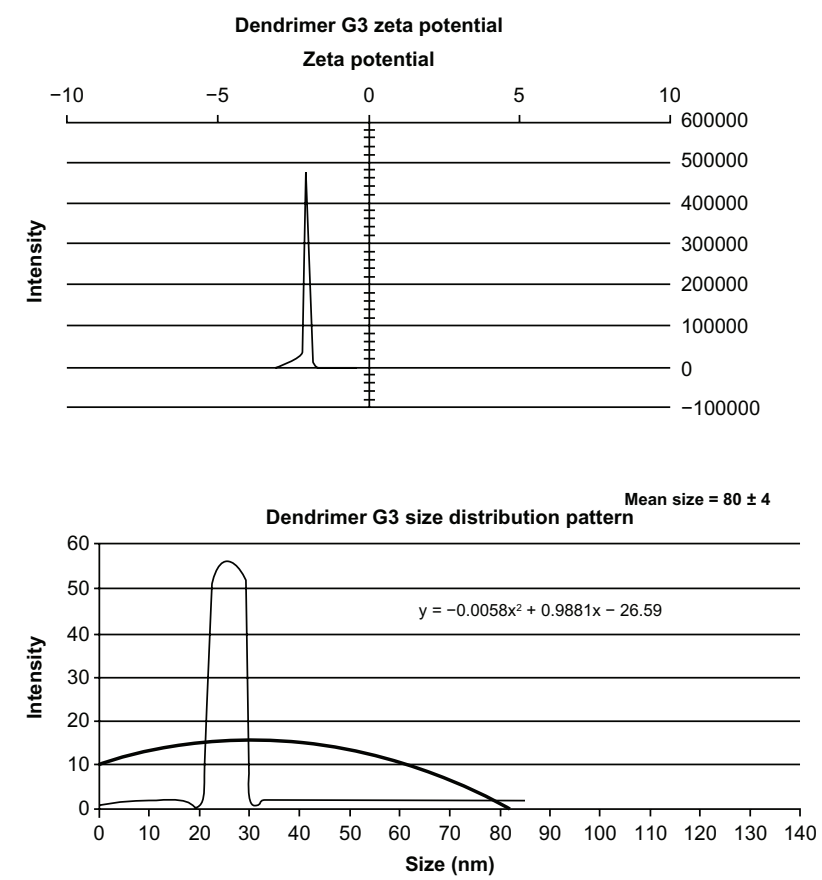

Figure 3 The obtained diagram for the size and charge determination of the nonconjugated dendrimers using the Zetasizer.

and oxygen peaks represent the existence of amino acidic compounds which were used in the drug protein structure. Therefore, it can be concluded that our drug protein was loaded in the interior space of this lipodendrosome particle. The tungsten (WM) peak presence also explains the existence
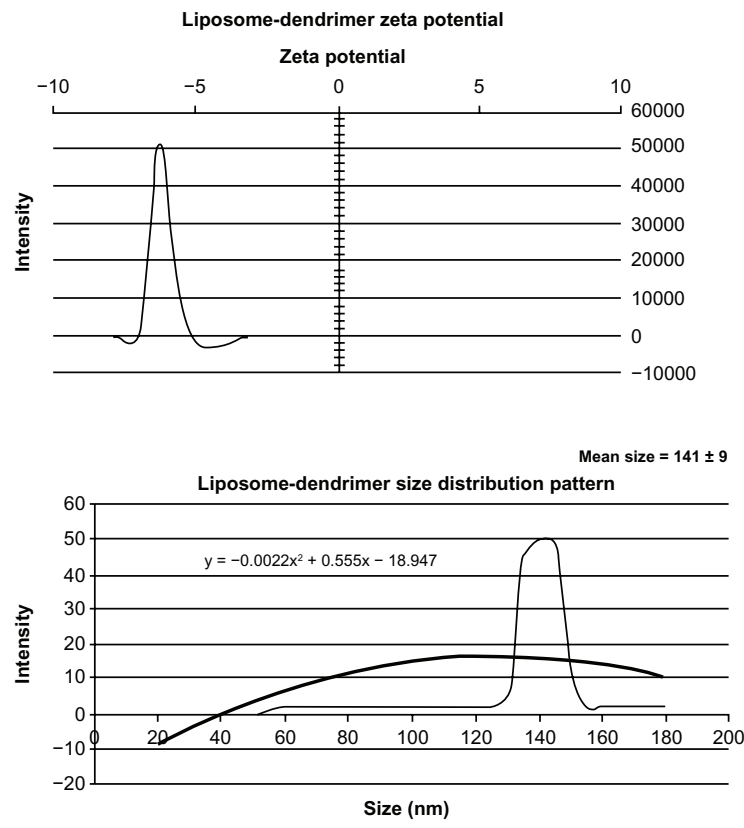

Figure 4 The obtained diagram for the size and charge determination of the synthetic conjugated nanolipodendrosome using the Zetasizer.
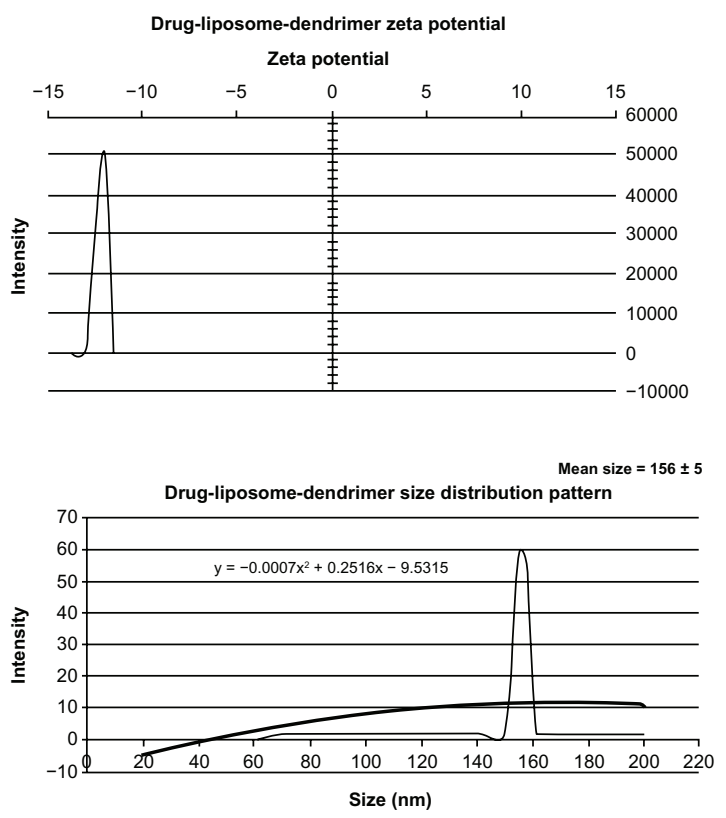

Figure 5 The obtained diagram for the size and charge determination of the synthetic drug loaded with conjugated nanolipodendrosome using the Zetasizer.

of phosphotungstic acid (color substance). The last observed peak (PK) is related to phosphor agent. Since phosphor is an indicator element in phospholipid and fatty acid compounds, it can be concluded that this peak relates to phospholipids used in a two-layer wall of liposome. The middle peak is related to the Na element whose salt is used to build dendrimer. Additionally, the oxygen peak implicates not only the existence of amino acids, but also a part of it is related to carboxylic agents used in dendrimer structure. The small peak appearing before the phosphor peak is related to the sulfur element used in some amino acid structures such as cysteine.

Figure 7E is related to EDX (Energy-dispersive X-ray Spectroscopy) characteristics of dendrimer-liposomes. As it is seen, the peak level of tungsten related to the staining material was much higher than its adjacent peaks and its equivalent peaks in the central area of Figure 7D. This is because of the PTA color accumulation entrapped in the space between dendrimers and the greater laser radiation

Table 2 The results of the samples analysis as mean \pm SD

\begin{tabular}{lcl}
\hline Particles & $\begin{array}{l}\text { Diameter } \pm \text { SD } \\
(\mathbf{n m})\end{array}$ & $\begin{array}{l}\text { Potential } \pm \text { SD } \\
(\mathbf{m V})\end{array}$ \\
\hline Liposome & $93 \pm 7$ & $-3.87 \pm 0.49$ \\
Dendrimer & $25 \pm 4$ & $-2.11 \pm 0.12$ \\
Liposome dendrimer & $141 \pm 9$ & $-6.33 \pm 1.12$ \\
Liposome dendrimer drug & $156 \pm 5$ & $-11.7 \pm 0.45$ \\
\hline
\end{tabular}

Abbreviation: SD, standard deviation. 


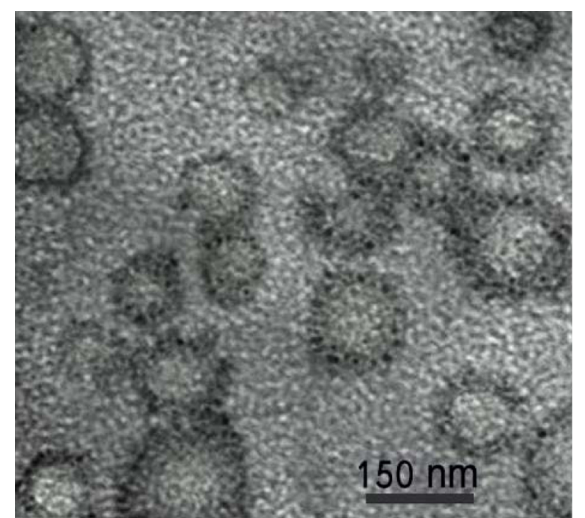

Figure 6 TEM images taken from the liposomes conjugated with dendrimer using PTA 2\%.

Note: The spheres have diameters of approximately $140 \mathrm{~nm}$.

Abbreviations: PTA, phosphotungstic acid; TEM, transmission electron microscopy.

distance covering in this area. Additionally, the peak related to dendrimers (sodium peak) is higher than its equivalent peak in Figure 7D. There is no peak related to phosphor (PK), nitrogen, hydrogen, or sulfur. The lack of phospholipids and protein combination can explain this issue. The carbon peak observed in this image is not related to the carbon used in fatty acid and phospholipids structures, but in the dendrimers structure. Comparing the oxygen peaks also shows us that this peak is much shorter than its equivalent peak in Figure 7D. This might be due to the lack of amino acids. Therefore, the oxygen used in the dendrimers structure as a carboxyl factor could explain this peak.

\section{Assessing the size and skeletal muscle volume of the mice in groups I, 3, and 5 by MRI}

The normal form of the body and muscles was observed in the model mouse in group 1 which had not received any drugs. Some inner parts such as the lung and liver were slightly visible (Figure $8 \mathrm{~A}$ ).

No significant muscle volume change was observed in the model mouse receiving nandrolone in group 3 (Figure 8B). The drug entered the systemic blood stream and went to other parts of the body and increased the protein and muscle volume. This increase is related to muscles like latissimus dorsi, biceps, biceps brachii, triceps brachii, and spinotrapezius femoris.

In the MRI obtained from the mouse receiving $2 \times$ dose of the candidate drug (Figure 8C), a volume increase was observed in the feet muscles. This increase is related to the muscles of biceps femoris, gastrocnemius, vastus lateralis, and some other feet muscles. There was not a significant change of volume in other muscles. Therefore, it can be concluded that our synthetic drug (MyoD factor part) has a local effect as a muscle builder stimulus and no effect or not much effect is seen in other parts of the body. The MRI showed no cysts or edemas in muscle tissues in the groups.

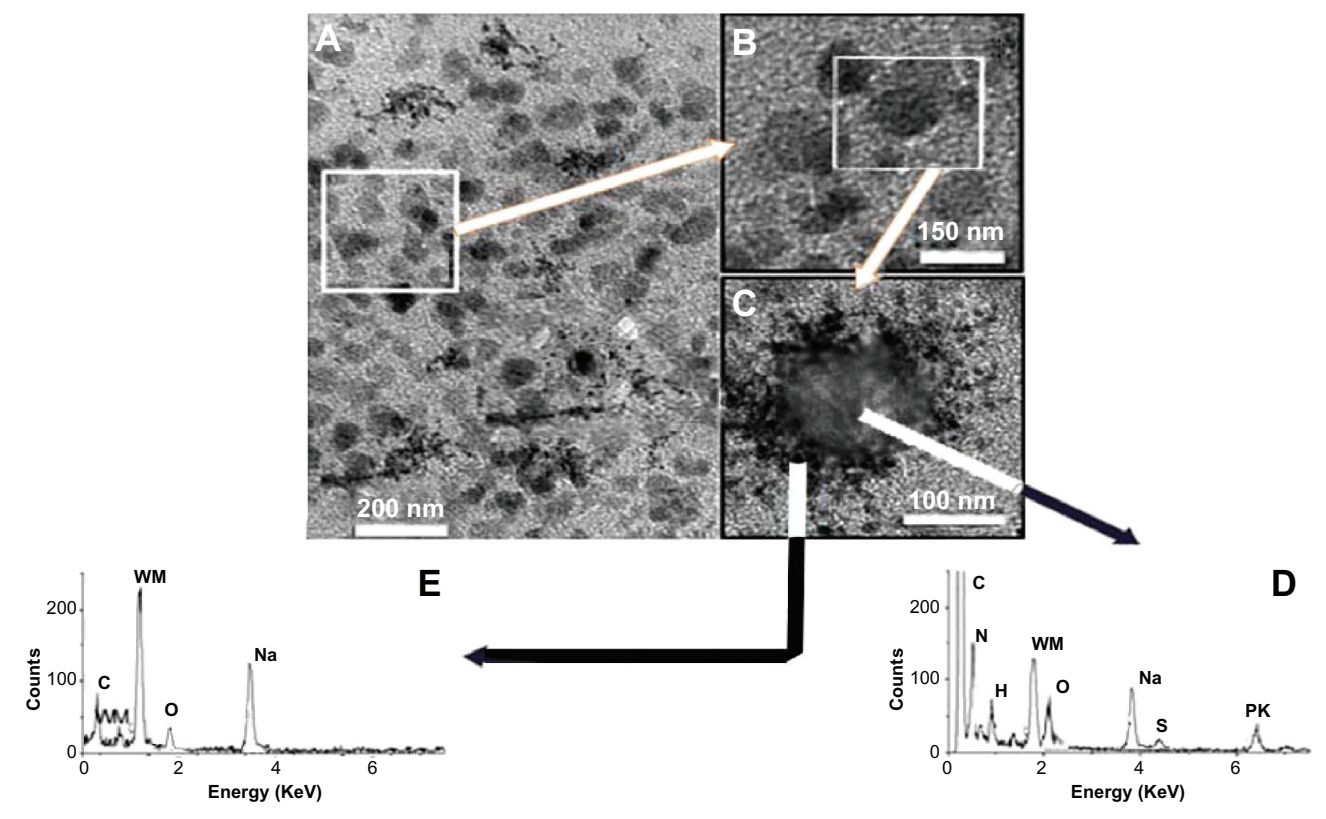

Figure 7 TEM image (A-C) taken from liposomes after loading the drug.

Note: The EDX spectrums obtained were compared with each other in (D) and (E).

Abbreviations: EDX, energy-dispersive X-ray; PK, phosphate of PTA; TEM, transmission electron microscopy; WM, tungsten. 


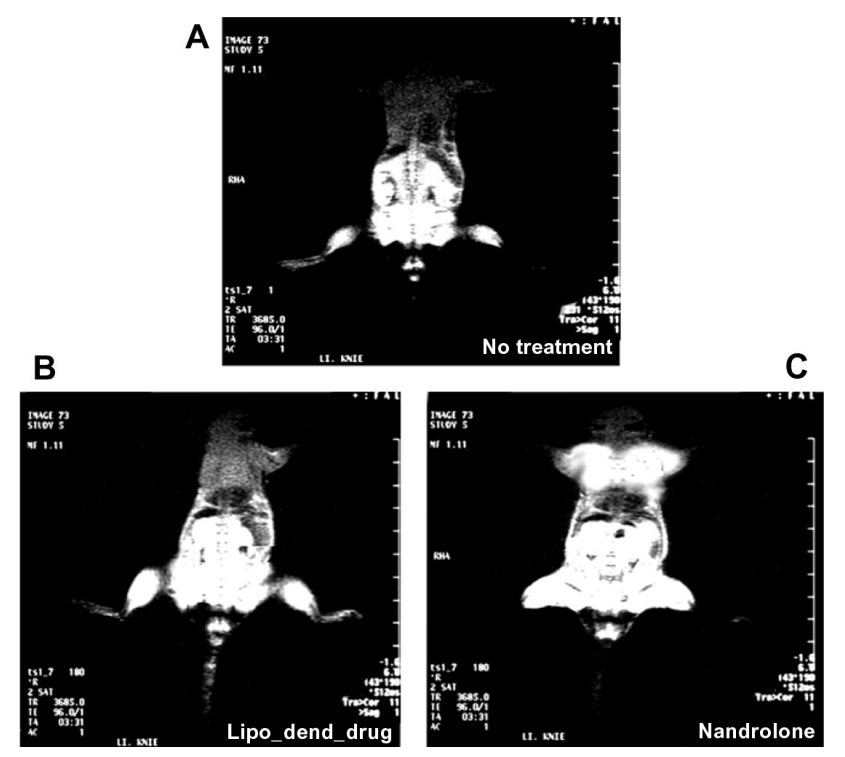

Figure 8 MRI from a mouse's muscle in (A) group I, (B) group 3, and (C) group 5 on day 14.

Abbreviations: MRI, magnetic resonance image; lipodend-drug, liposome-dendrimerglatiramer acetate + MyoD.

\section{Pathobiology assessment and evaluation of mouse skeletal muscles in groups I, 3, and 5}

The sample muscle in this study for cutting and staining was biceps femoris, because this part and the trapezius are sensitive to muscle building stimulus drugs and they have greater growth and creation of nuclei than other muscles.

The histology images are shown in Figure 9. In the image related to a mouse in group 1 , myofibrils are not recognizable enough and the tissue seems integrated. Muscular cells are not in order and they do not have a clear demarcation. These cells are recognizable as pale dots and in a low number. On the other hand, the myofibrils in the image showing the mouse receiving nandrolone were more massive and in order. In fact, it shows the increase of protein making in the skeletal muscles. The number of muscular cells in each slide had no significant difference compared to the control. The nuclei seemed bold and numerous.

In the image showing the mouse treated with the synthetic nanodrug $(2 \times$ dose $)$, myofibrils that were more linear and in order were observed. Muscular cells were numerous but low in volume in comparison with their identical cells in the nandrolone receiver model. Since the MyoD factor is necessary in transforming satellite cells into myoblasts - these myoblasts will change into myotubes when exposed to other factors like myogenin and MRF4 - the increase in the number of muscular cells in this image is justifiable.

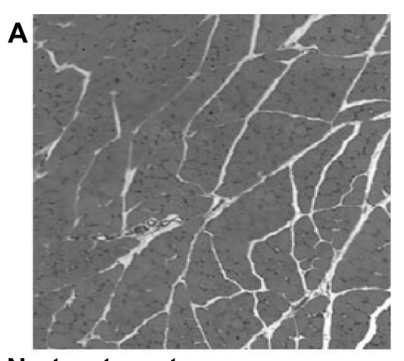

No treatment

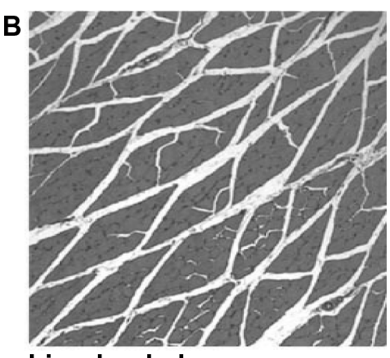

Lipodend_drug

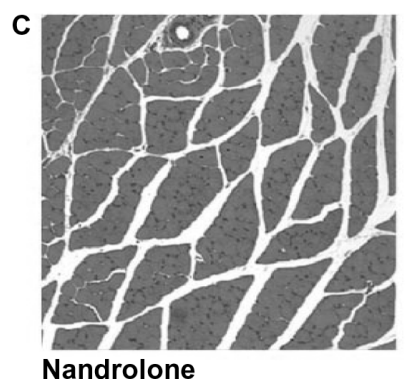

Nandrolone

Figure 9 Histology images showing the muscles of three mice in (A) group I, (B) group 3, and (C) group 5 on day 14 .

Abbreviation: Lipodend-drug, liposome-dendrimer-glatiramer acetate + MyoD

\section{Evaluating the surface markers of CD4+ and CD8+ of T lymphocytes in blood samples received from three mice in groups I, 3, and 5 using a flow cytometer}

For 28 days, blood was sampled from the mice in groups 1 , 3 , and 5 on days $1-7,12,14,22$ and 28 after the injection, and the changes in $\mathrm{CD} 4+/ \mathrm{CD} 8+$ related to $\mathrm{T}$ lymphocytes were evaluated with a flow cytometer (Bio-Rad Laboratories S3 ${ }^{\text {TM }}$ Cell Sorter; Hercules, CA, USA). Figure 10 shows the change in percentage of $\mathrm{CD} 4+/ \mathrm{CD} 8+$ for the mice receiving the $2 \times$ dose drug in comparison with the normal level in group 1 on each day and Table 3 shows the results as mean \pm standard deviation.

The change in percentage of CD4+/CD8+ of nanodrug receivers in comparison with the normal level in group 1 decreased significantly $(P<0.05)$ from day 5 to day 7 . On the contrary, this percentage increased from day $12 \mathrm{on}$. Between day 7 and day 28 and also between the day 1 and day 28 , statistical differences were observed $(P<0.001)$. In week 2 there was a statistical difference $(P<0.01)$. No statistical difference was observed in the weeks 3 and $4(P>0.05)$.

The marker for CD4+ decreased in the first 7 days, while the marker for CD8+ had a fixed concentration. On the other hand, both markers decreased from day 12 on. Figure 11 shows the change in percentage of $\mathrm{CD} 4+/ \mathrm{CD} 8+$ for the mice in the control group (nandrolone receivers) in comparison 


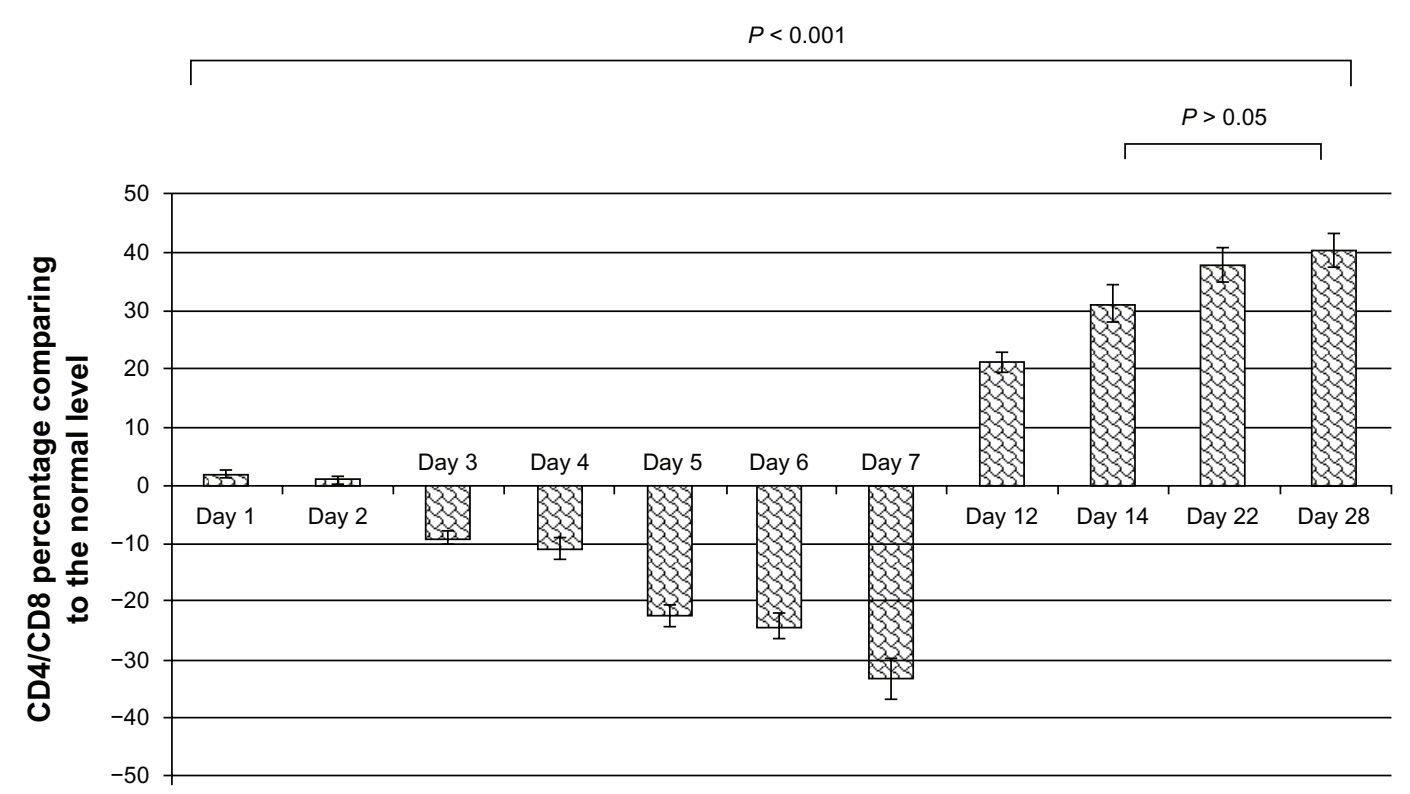

Figure 10 The ratio of CD4+/CD8+ from the blood samples of the mice receiving $2 \times$ dose of liposome-dendrimer-glatiramer acetate + MyoD.

Table 3 The data obtained from the average percentage of change of CD4+/CD8+ of drug receivers in comparison with group I

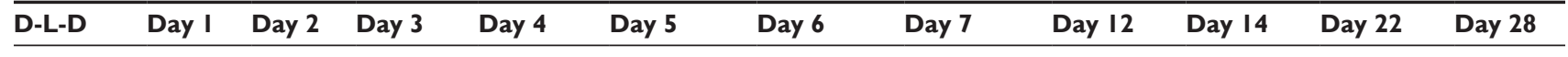

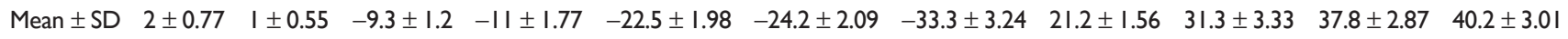
Abbreviations: SD, standard deviation; D-L-D, dendrimer-liposome-drug.

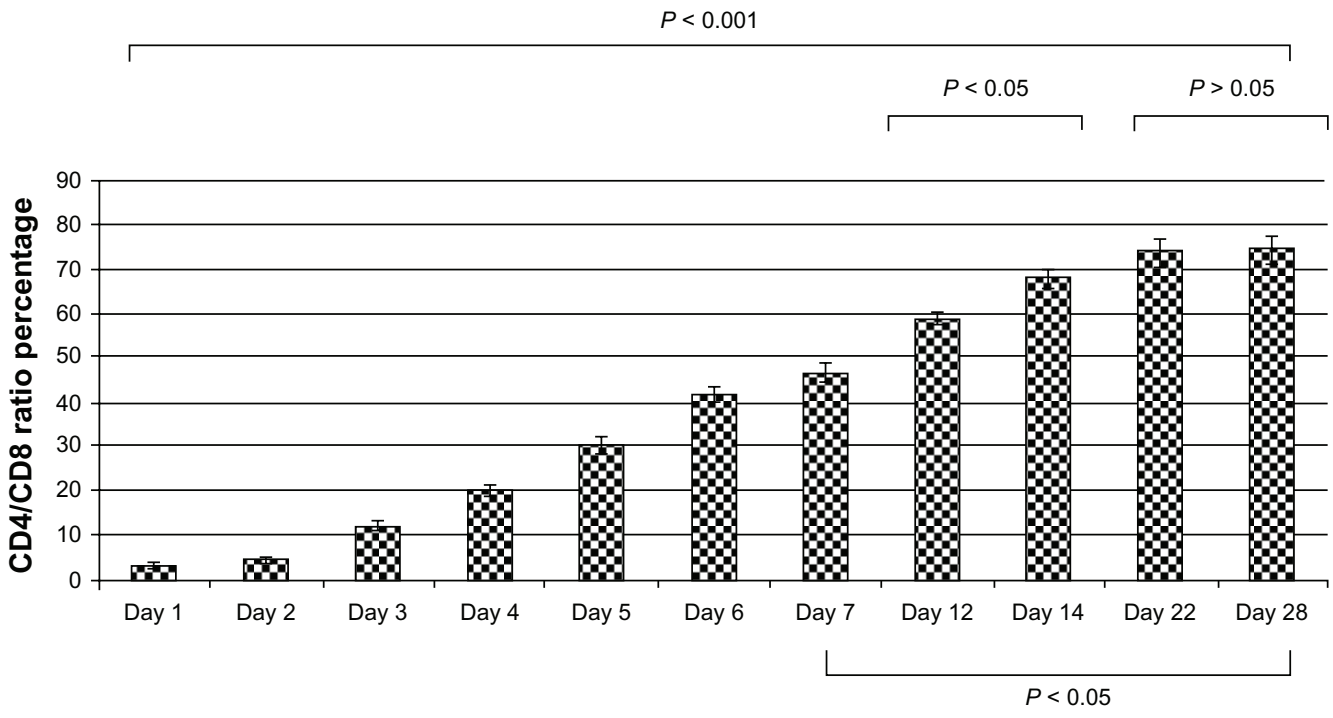

Figure II The diagram showing the ratio of CD4+/CD8+ of the blood samples from the nandrolone receiver model.

Table 4 The data obtained from the average percentage of change of CD4+/CD8+ in the nandrolone receiver group in comparison with group I

\begin{tabular}{|c|c|c|c|c|c|c|c|c|c|c|c|}
\hline Nandrolone & Day I & Day 2 & Day 3 & Day 4 & Day 5 & Day 6 & Day 7 & Day 12 & Day 14 & Day 22 & Day 28 \\
\hline Mean \pm SD & $3.3 \pm 0.66$ & $4.2 \pm 0.54$ & $12 \pm 1$ & $19.9 \pm 1.09$ & $30.2 \pm 2.02$ & $41.4 \pm 1.98$ & $46.5 \pm 1.88$ & $58.7 \pm 1.56$ & $67.77 \pm 2.33$ & $73.6 \pm 3.21$ & $74.1 \pm 2.89$ \\
\hline
\end{tabular}

Abbreviation: SD, standard deviation. 


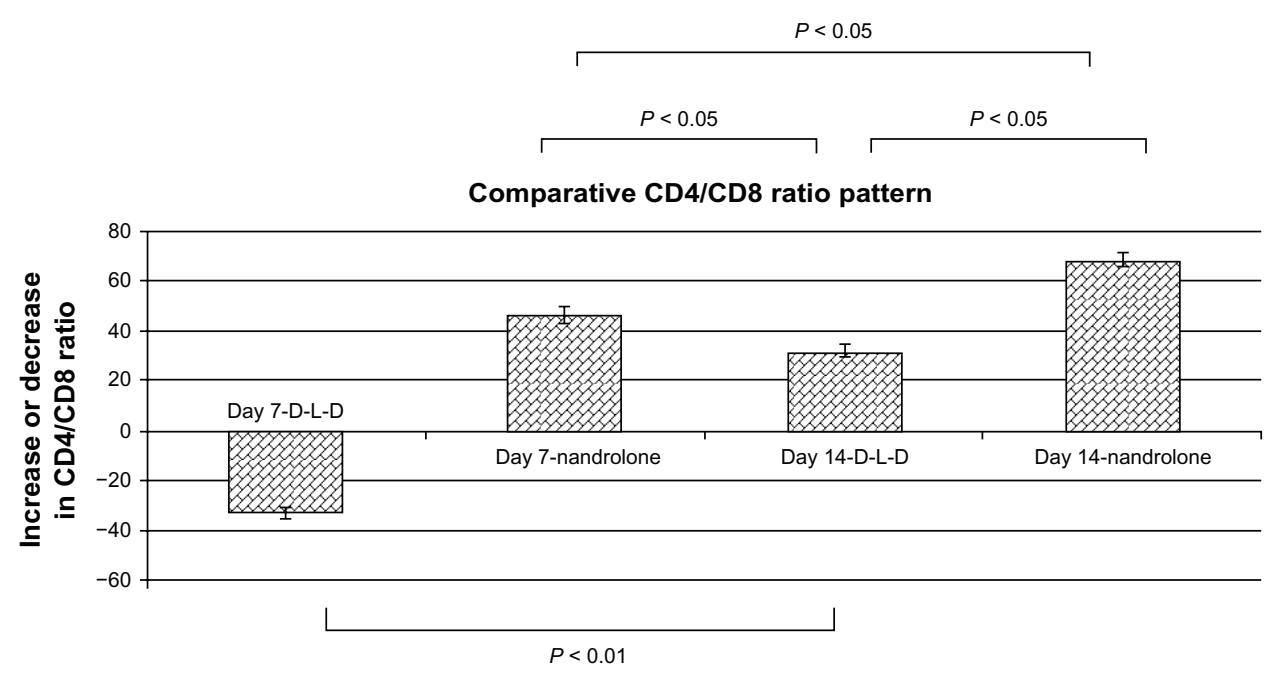

Figure 12 The comparison diagram of the ratio of CD4+/CD8+ of the blood samples from the model mice receiving nandrolone and $2 \times$ dose of drug. Abbreviation: D-L-D, dendrimer-liposome-drug.

with the normal level in group 1 on each day, and Table 4 shows the results as mean \pm standard deviation.

The average change in percentage of $\mathrm{CD} 4+/ \mathrm{CD} 8+$ in comparison with the normal level (group 1) in the nandrolone receiver model increased from day 5 on, while there was a statistical difference between day 1 and day $28(P<0.001)$. There was also a statistical difference during the time between day 7 and day $14(P<0.05)$. But no statistical difference was observed between day 14 and day $28(P>0.05)$. Additionally, a significant statistical difference was observed between day 7 and day $28(P<0.05)$. Both markers of CD4+ and $\mathrm{CD} 8+$ decreased in comparison with the normal level after the nandrolone injection.
In Figure 12, the ratio of changes in CD4+/CD8+ of the nanolipodendrosome drug is compared with nandrolone. The nanolipodendrosome drug had a significant difference on day 7 and day $14(P<0.01)$ compared to the control group (untreated group), and comparing with the nandrolone receiver model on the same days, there was another significant difference $(P<0.05)$. Having compared the ratio diagram of $\mathrm{CD} 4+/ \mathrm{CD} 8+$ on day 7 of the nandrolone receiver model with the nanolipodendrosome drug receiver model on day 14 , a significant difference was observed $(P<0.05)$. The statistical comparison between lipodendrosome and nandrolone showed that nandrolone, statistically $(P<0.05)$, was more powerful than lipodendrosome in modifying the immune system.

\section{Day 1}

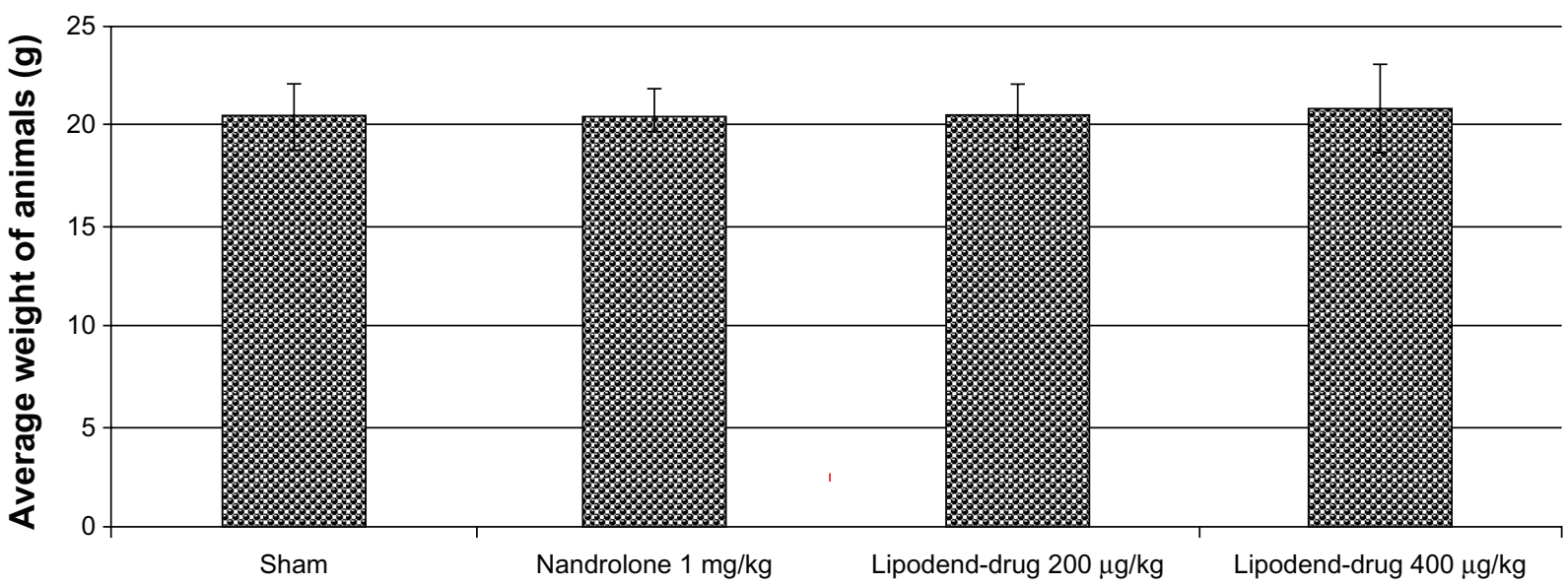

Figure 13 The data obtained from the average weight of the mice in the four groups of the experiment on day I.

Abbreviation: Lipodend-drug, lipodendrosome drug. 


\section{Evaluating the physical characteristics} of the mice in groups I, 3 , and 5 on day $I$ and in week 2 and week 4

In the abnormal conjugated toxicity test, no mortality toxicity of the lipodendrimer drug was observed.

\section{The statistical comparison of the mouse weights in the four groups of the experiment on day I}

The average weight of the mice in the four groups on day 1 after the injection is shown in Table 5 and Figure 13. No significant difference was observed between the average weight of the mice in the four groups on day 1 (Figure $13 ; P>0.05$ ). Therefore, the assumption that the average weight was equal among the four groups was accepted $(P<0.05)$.

\section{The statistical comparison of mouse weights in all four groups of the experiment on day 14}

The average weight of all mice in all four groups on the first day after the injection is shown in Table 6 and Figure 14. Comparing the average weight of group 1 and the other two groups receiving nandrolone and $2 \times$ dose of the synthetic nanodrug and the two other groups receiving nandrolone and $1 \times$ dose of the nanodrug showed that there was a significant difference $(P<0.05)$.

\section{Statistical comparison of mouse weights in all four groups of the experiment on day 28}

The average mouse weight in all four groups on the first day after the injection is shown in Table 7 and Figure 15. It was observed that the $2 \times$ dose of synthetic nanodrug and nandrolone increased the receivers' weights significantly on day 28 in comparison with receivers of the $1 \times$ dose and group 1 .

\section{Comparison of the weight of group I on three different days}

Comparing the mice in group 1 on three days $(1,14$, and 28) shows that there was a significant difference in this group on day 1 and day $28(P<0.05)$. This may be due to the natural growth and maturity of the animal in this period (Figure 16).

\section{Weight comparison of the mice in the control group on three different days}

Nandrolone is a very strong synthetic steroid-androgen which can increase the muscular mass and animal's volume and weight in a very short interval. Therefore, as expected, comparing this group on day 1 and day 28, a significant difference $(P<0.05)$ in weight average was observed (Figure 17).

\section{Comparing the weight of the groups receiving both $I \times$ and $2 \times$ doses of nanodrug on three different days}

On day 28 , the group receiving the $2 \times$ dose had a significant difference in comparison with the group receiving the $1 \times$ and $2 \times$ doses on day 1 . The $2 \times$ dose on day 14 , in comparison with the group receiving the $2 \times$ dose on the first day, also showed a significant difference in average weight $(P<0.05)$ (Figure 18).

\section{Comparing the groups receiving the control drug and the high concentration nanodrug}

Comparing the two groups receiving nandrolone on day 14 and day 28 and the group receiving the $2 \times$ dose of synthetic drug on day 28 , no significant difference in average weight between these three groups was observed $(P<0.05)$ (Figure 19). This shows the strong influence of the nanodrug containing the MyoD factor in muscle building and increasing the mass and volume of animal skeletal muscle, even though it was local.

\section{Conclusion}

In this study after performing quantitative and qualitative assessments of nanoparticles and the proper position of dendrimers on a liposome surface, drug encapsulation within the nano-carrying lipoprotein dendrosome was ensured.

Table 5 The data obtained from the average weight of the mice in the four groups of the experiment on day I

\begin{tabular}{lllll}
\hline & $\begin{array}{l}\text { Control } \\
\text { vehicle }\end{array}$ & $\begin{array}{l}\text { Nandrolone } \\
\text { I } \mathbf{~ m g / k g}\end{array}$ & Lipodend-drug & Lipodend-drug \\
& $\mathbf{2 0 0 \mu \mathrm { g } / \mathbf { k g }}$ & $\mathbf{4 0 0 \mu \mathbf { g } / \mathbf { k g }}$ \\
\hline Weight day I & $20.2 \pm 1.007$ & $20.77 \pm 1.367$ & $20.2 \pm 1.658$ & $19.91 \pm 1.887$ \\
\hline
\end{tabular}

Abbreviation: Lipodend-drug, lipodendrosome drug. 
Table 6 The data obtained from the average weight of all mice in all four groups of the experiment in week 2

\begin{tabular}{|c|c|c|c|c|}
\hline & $\begin{array}{l}\text { Control } \\
\text { vehicle }\end{array}$ & $\begin{array}{l}\text { Nandrolone } \\
\mathrm{I} \mathrm{mg} / \mathrm{kg}\end{array}$ & $\begin{array}{l}\text { Lipodend-drug } \\
200 \mu \mathrm{g} / \mathrm{kg}\end{array}$ & $\begin{array}{l}\text { Lipodend-drug } \\
400 \mu \mathrm{g} / \mathrm{kg}\end{array}$ \\
\hline Weight day 14 & $25.56 \pm 1.955$ & $36.54 \pm 1.671$ & $30.69 \pm 1.964$ & $35.17 \pm 2.135$ \\
\hline
\end{tabular}

Abbreviation: Lipodend-drug, lipodendrosome drug.

Table 7 The data obtained from the average of all mouse weights of all four groups in week 4

\begin{tabular}{|c|c|c|c|c|}
\hline & $\begin{array}{l}\text { Control } \\
\text { vehicle }\end{array}$ & $\begin{array}{l}\text { Nandrolone } \\
\mathrm{I} \mathrm{mg/kg}\end{array}$ & $\begin{array}{l}\text { Lipodend-drug } \\
200 \mu \mathrm{g} / \mathrm{kg}\end{array}$ & $\begin{array}{l}\text { Lipodend-drug } \\
400 \mu \mathrm{g} / \mathrm{kg}\end{array}$ \\
\hline Weight day 28 & $30.9 \pm 1.054$ & $48.08 \pm 1.115$ & $39.91 \pm 1.646$ & $43.02 \pm 1.560$ \\
\hline
\end{tabular}

Abbreviation: Lipodend-drug, lipodendrosome drug.

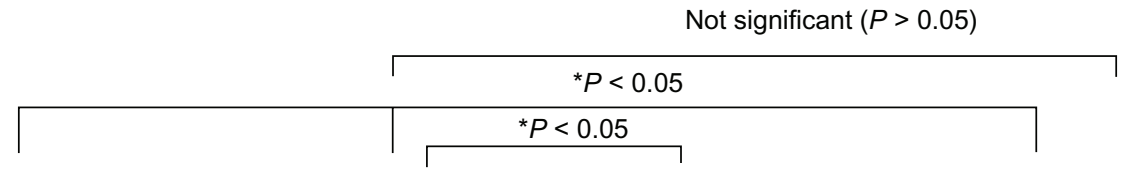

Day 14

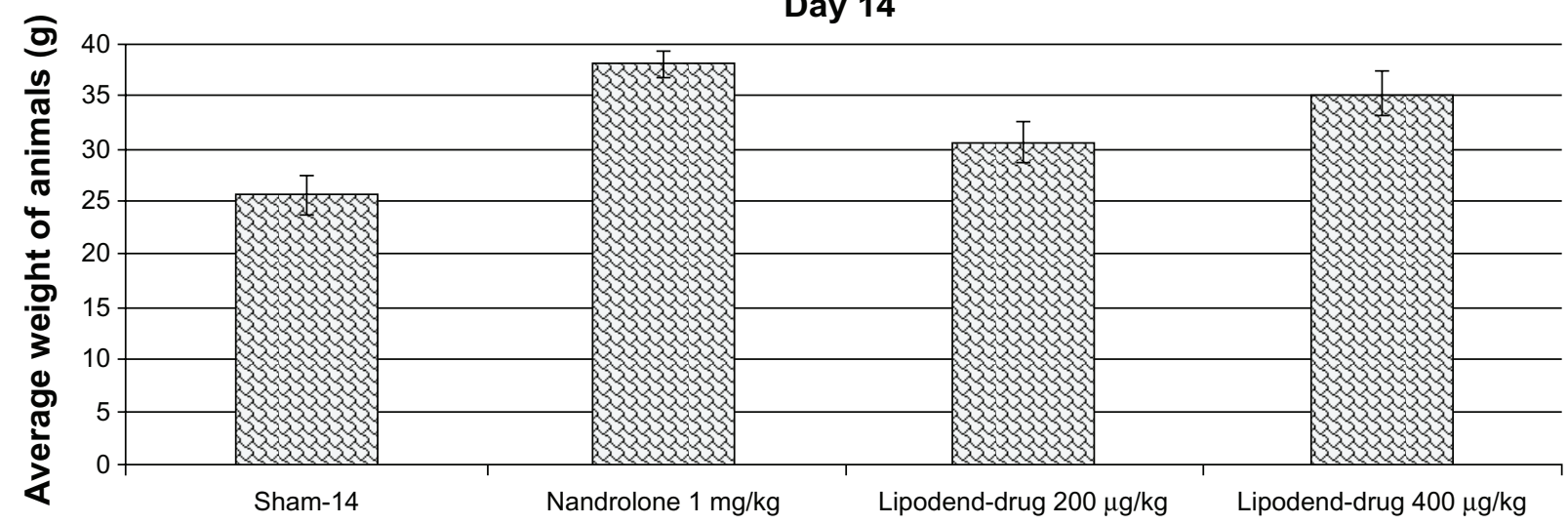

Figure 14 Diagram of the data obtained from the average weight of all mice in all four groups of the experiment in week 2.

Abbreviation: Lipodend-drug, lipodendrosome drug.

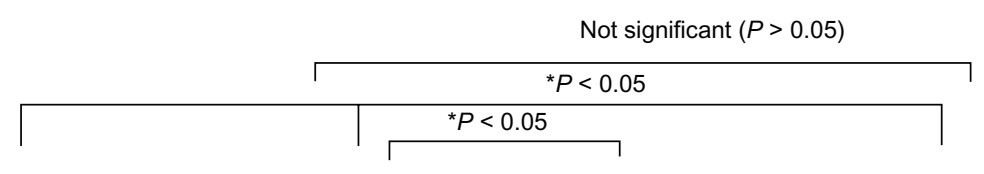

Day 28

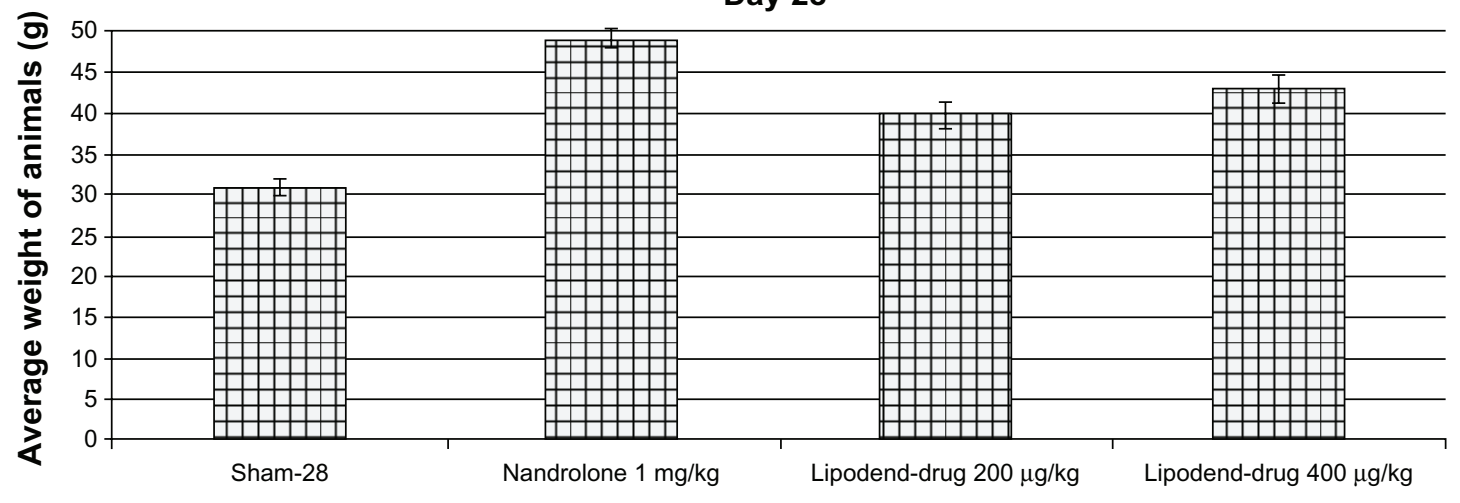

Figure 15 The diagram of the data obtained from the average of all mouse weights in all four groups in week 4.

Abbreviation: Lipodend-drug, lipodendrosome drug. 


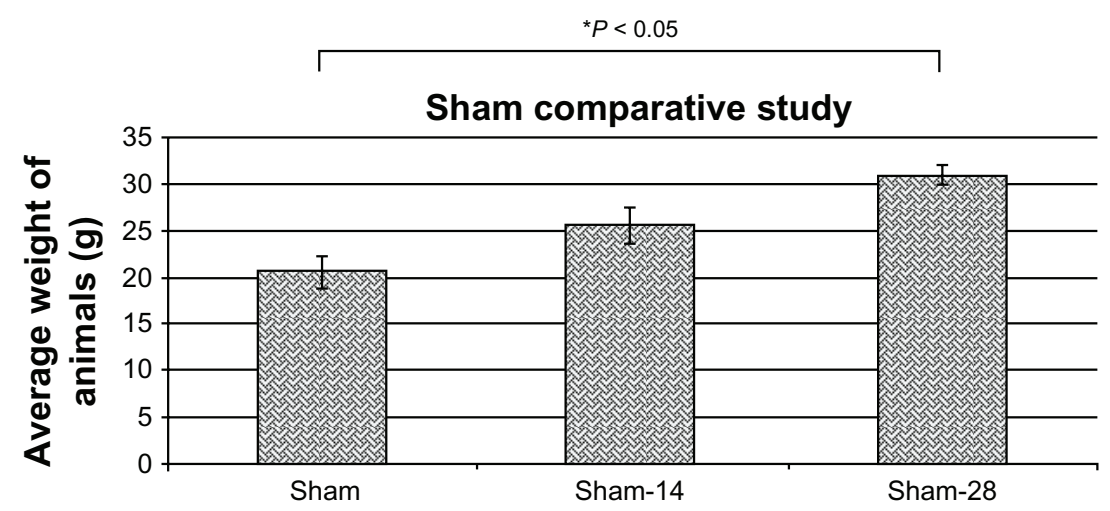

Figure 16 Comparison between diagrams of weight growth in mice of group I on three different days.

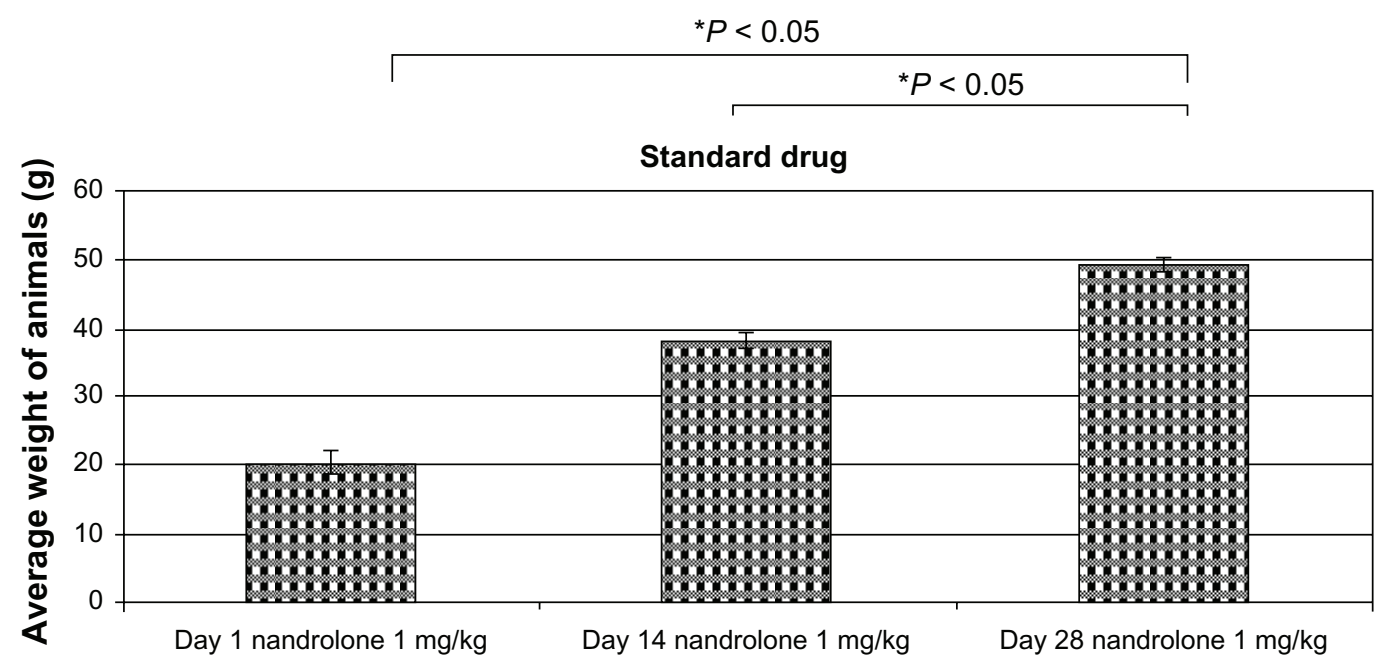

Figure 17 Comparing the weight growth diagrams of the mice in the control group on three different days.

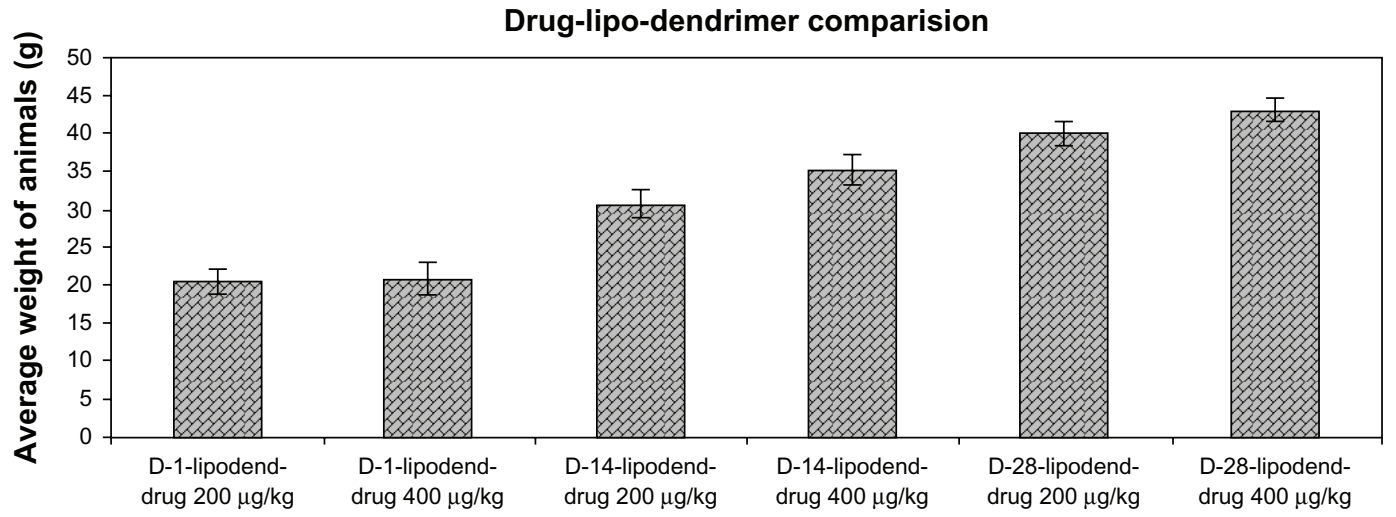

Figure 18 The diagrams comparing the weight growth of the mice treated with the $I \times$ and $2 \times$ doses of synthetic drug on three different days ( 1 , I4, and 28 ). Abbreviations: Lipodend-drug, lipodendrosome drug; D-I, day I; D-14, day 14; D-28, day 28.

Next, the effectiveness of the MyoD factor in regenerating skeletal muscle and reducing the effect of GA drug on the immune system were confirmed in vitro (see Supplementary materials) and in vivo. In most studies that have been carried out on the effects of the MyoD factor on skeletal muscle, the same foreign agent, such as a gene carrier plasmid or other drugs, has been used as a synthesis stimulus for MyoD in normal mice or a dystrophy model. ${ }^{19,31,42}$ But in this research, 


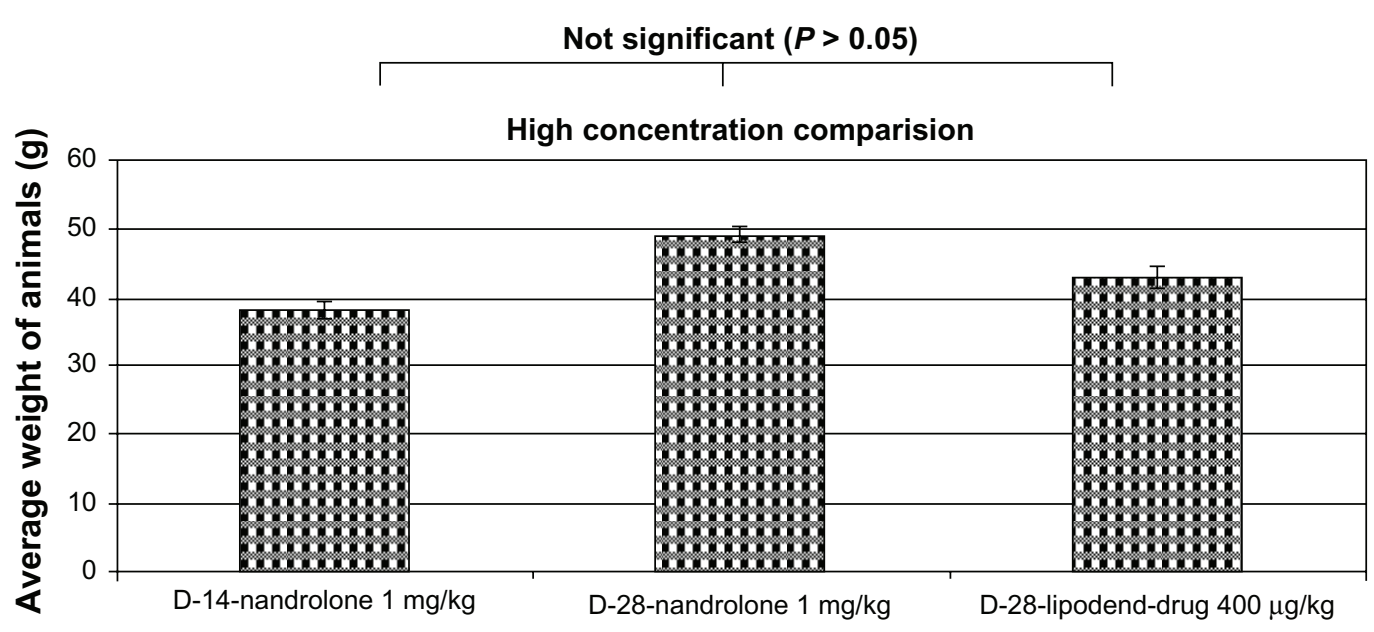

Figure 19 The comparison diagram between the groups receiving nandrolone on day I4 (D-I4) and 28 (D-28) and also the group receiving the $2 \times$ dose of synthetic drug on day 28 . Abbreviation: Lipodend-drug, lipodendrosome drug.

the MyoD factor was inserted exogenously into the cell using nanolipodendrosome. The results obtained from the mice under treatment with this nanodrug showed a local, but very powerful, effect on skeletal muscle in the lower part of body.

Also, in this study, two doses of drug injection, $200 \mu \mathrm{g} / \mathrm{kg}$ and $400 \mu \mathrm{g} / \mathrm{kg}$, were used, while the amount of injected drugs in other studies has been much greater than these amounts. ${ }^{5,6,14,15}$ In addition, by using this technology, the doses of used drug interval reduced and it could reduce patients' referrals to a clinic. Additionally, in the current experiment, $\mathrm{C} 2 \mathrm{C} 12$ mouse adherent myoblasts were cultured and exposed to dendrimer-liposome-drug and surprisingly, a significant $(P<0.05)$ cell proliferation enhancement was observed at high dose $400 \mathrm{nM}, 48$ hours after exposure. The findings support in vivo pathophysiological observations (see Supplementary materials).

In many cases, modifying the immune system can provide the ideal conditions for different purposes (eg, effect of GA medicine). The effect of injecting the nanodrug containing GA on the immune system was proved by reducing the two markers of CD4+ and CD8+ compared with the normal level. These results correspond with the results of researchers such as Aharoni et al and Nagata et al. 7,9,30,42

Although the results of this study are promising for a novel anti-dystrophy factor, further research is required. It has been proposed that the simultaneous treatment of GA with the suppressor of transforming growth factor beta (TGF- $\beta$; using its profibrotic activities) can potentially improve the clinical and histological results. ${ }^{3}$ Furthermore, using other myogenic factors like MRF4 and myogenin, which, along with MyoD, accelerate muscular differentiation and regeneration effectively, can improve skeletal muscles more. Finally, in the nanotechnology section, it can be useful to insert antibodies specifically for skeletal muscular cells on the surface of liposomes or on the branches of dendrimers in order to target the drug at the muscular tissues and minimize the drug's side effects on other parts of the body.

\section{Acknowledgments}

This research is a major part of an MSc thesis in Biochemistry by Mr Ehsan Afzal. This study was supported by the Pasteur Institute of Iran as well as the MR Imaging Center of Imam Khomeini Hospital, Tehran University of Medical Sciences, and Shiraz University of Medical Sciences. The authors wish to thank all technicians who provided support during the course of research.

\section{Disclosure}

The authors report no conflicts of interest in this work.

\section{References}

1. Angelini C. Neuromuscular diseases: advances in therapy and diagnosis. Lancet Neurol. 2012;11(1):15-17.

2. Amanzur Y, Muntoni F. Diagnosis and new treatments in muscular dystrophies. J Neurol Neurosurg Psychiatry. 2009;80(7):706-714.

3. Arnon R, Aharoni R. Mechanism of action of Glatiramer acetate in multiple sclerosis and its potential for the development of new applications. Proc Natl Acad Sci U S A. 2004;101(Suppl 2):14593-14598.

4. Assani A, Moundanga S, Beney L, Gervais P. Vesicle formation in the membrane of onion cells (Allium cepa) during rapid osmotic dehydration. Ann Bot. 2009;104(7):1389-1395.

5. Amstad E, Reimhult E. Nanoparticle actuated hollow drug delivery vehicles. Nanomedicine (Lond). 2012;7(1):145-164.

6. Haririan I, Alavidjeh MS, Khorramizadeh MR, Ardestani MS, Ghane ZZ, Namazi H. Anionic linear-globular dendrimer-cis-platinum (II) conjugates promote cytotoxicity in vitro against different cancer cell lines. Int $J$ Nanomedicine. 2010;5:63-75. 
7. Aharoni R, Yussim A, Sela M, Arnon R. Combined treatment of glatiramer acetate and low doses of immunosuppressive drugs is effective in the prevention of graft rejection. Int Immunopharmacol. 2005;5(1): 23-32.

8. Mann AP, Bhavane RC, Somasunderam A, et al. Thioaptamer conjugated liposomes for tumor vasculature targeting. Oncotarget. 2011;2(4): 298-304.

9. Aharoni R. The mechanism of action of glatiramer acetate in multiple sclerosis and beyond. Autoimmun Rev. 2013;12(5):543-553.

10. Dabiré H, Barthélémy I, Blanchard-Gutton N, et al. Vascular endothelial dysfunction in Duchenne muscular dystrophy is restored by bradykinin through upregulation of eNOS and nNOS. Basic Res Cardiol. 2012;107(1):240.

11. Balagopal P, Olney R, Darmaun D, et al. Oxandrolone enhances skeletal muscle myosin synthesis and alters global gene expression profile in Duchenne muscular dystrophy. Am J Physiol Endocrinol Metab. 2006;290(3):E530-E539.

12. Wang B, Zhang L, Bae SC, Granick S. Nanoparticle-induced surface reconstruction of phospholipid membranes. Proc Natl Acad Sci USA. 2008;105(47):18171-18175.

13. Choi JH, Adams SM, Ragan R. Design of a versatile chemical assembly method for patterning colloidal nanoparticles. Nanotechnology. 2009;20(6):065301.

14. Zhao D, Zhao X, Zu Y, et al. Preparation, characterization, and in vitro targeted delivery of folate-decorated paclitaxel-loaded bovine serum albumin nanoparticles. Int J Nanomedicine. 2010;5:669-677.

15. Pourasgari F, Ahmadian S, Salmanian AH, Sarbolouki MN, Massumi M. Low cytotoxicity effect of dendrosome as an efficient carrier for rotavirus VP2 gene transferring into a human lung cell line : dendrosome, as a novel intranasally gene porter. Mol Biol Rep. 2009;36(1):105-109.

16. Cossu G, Sampaolesi M. New therapies for Duchenne muscular dystrophy: challenges, prospects and clinical trials. Trends Mol Med. 2007;13(12):520-526.

17. Graf ER, Heerssen HM, Wright CM, Davis GW, DiAntonio A. Stathmin is required for stability of the Drosophila neuromuscular junction. J Neurosci. 2011;31(42):15026-15034.

18. Ikegawa H, Kuwagata Y, Hayakawa K, Noguchi K, Ogura H, Sugimoto H. Effects of exchange transfusion with liposome-encapsulated hemoglobin on $\mathrm{VO}_{2} / \mathrm{DO}_{2}$. Artif Organs. 2012;36(2):130-138.

19. Anderson JE, McIntosh LM, Moor AN, Yablonka-Reuveni Z. Levels of MyoD protein expression following injury of $\mathrm{mdx}$ and normal limb muscle are modified by thyroid hormone. J Histochem Cytochem. 1998;46(1):59-67.

20. Kirby CJ, Gregoriadis G. Liposome Formulation. In: Gregoriadis G. Liposome Technology, Volume I: Liposome Preparation and Related Techniques. 2nd ed. Boca Raton: CRP press; 1984:13-140.

21. Kawano K, Takayama K, Nagai T, Maitani Y. Preparation and pharmacokinetics of pirarubicin loaded dehydration-rehydration vesicles. Int J Pharm. 2003;252(1-2):73-79.

22. Li L, Zhang Y, Han S, et al. Penetration enhancement of lidocaine hydrochlorid by a novel chitosan coated elastic liposome for transdermal drug delivery. J Biomed Nanotechnol. 2011;7(5):704-713.

23. Mokalled MH, Johnson AN, Creemers EE, Olson EN. MASTR directs MyoD-dependent satellite cell differentiation during skeletal muscle regeneration. Genes Dev. 2012;26(2):190-202.

24. Marques MJ, Oggiam DS, Barbin IC, Ferretti R, Santo Neto H. Long-term therapy with deflazacort decreases myocardial fibrosis in mdx mice. Muscle Nerve. 2009;40(3):466-468.
25. Mady MM, Shafaa MW, Abbase ER, Fahium AH. Interaction of doxorubicin and dipalmitoylphosphatidylcholine liposomes. Cell Biochem Biophys. 2012;62(3):481-486.

26. Jain KK. Nanodiagnostics: application of nanotechnology in molecular diagnostics. Expert Rev Mol Diagn. 2003;3(2):153-161.

27. Mufamadi MS, Pillay V, Choonara YE, et al. A review on composite liposomal technologies for specialized drug delivery. J Drug Deliv. 2011;2011:939851.

28. Marques MJ, Oggiam DS, Barbin IC, Ferretti R, Santo Neto H. Long-term therapy with deflazacort decreases myocardial fibrosis in mdx mice. Muscle Nerve. 2009;40(3):466-468.

29. Milo R, Panitch H. Additive effects of copolymer-1 and interferon beta-1b on the immune response to myelin basic protein. $J$ Neuroimmunol. 1995;61(2):185-193.

30. Nagata R, Kamimura D, Suzuki Y, et al. A case of nemaline myopathy with associated dilated cardio myopathy and respiratory failure. Int Heart J. 2011;52(6):401-405.

31. Qin RF, Mao TQ, Gu XM, et al. Regulation of skeletal muscle differentiation in fibroblasts by exogenous MyoD gene in vitro and in vivo. Mol Cell Biochem. 2007;302(1-2):233-239.

32. Ansell SM, Harasym TO, Tardi PG. Antibody Conjugation Methods for Active Targeting of Liposomes. Methods in Molecular Medicine; Vol. 25: Drug Targeting: Strategies, Principles, and Applications. Francis GE, editor. Secaucus, NJ, USA: Springer; 2000.

33. Spencer MJ, Tidball JG. Do immune cells promote the pathology of dystrophin-deficient myopathies? Neuromuscul Disord. 2001;11(6-7): 556-564.

34. Beenakker EA, Fock JM, Van Tol MJ, et al. Intermittent prednisone therapy in Duchenne muscular dystrophy: a randomized controlled trial. Arch Neurol. 2005 Jan;62(1):128-132.

35. Abe $\mathrm{S}$, Rhee $\mathrm{S}$, Iwanuma $\mathrm{O}$, et al. Effect of mechanical stretching on expressions of muscle specific transcription factors MyoD, Myf-5, myogenin and MRF4 in proliferated myoblasts. Anat Histol Embryol. 2009;38(4):305-310.

36. Sutherland DR, Kuek N, Davidson J, et al. Diagnosing PNH with FLAER and multiparameter flow cytometry. Cytometry B Clin Cytom. 2007;72(3):167-177.

37. Talim B, Kale G, Topaloglu H, et al. Clinical and histopathological study of merosin-deficient and merosin-positive congenital muscular dystrophy. Pediatr Dev Pathol. 2000;3(2):168-176.

38. Tidball JG. Inflammatory processes in muscle injury and repair. Am J Physiol Regul Integr Comp Physiol. 2005;288(2):R345-R353.

39. Van Opstal N, Verlinden C, Myncke J, Goemans N, Moens P. The effect of Luque-Galveston fusion on curve, respiratory function and quality of life in Duchenne muscular dystrophy. Acta Orthop Belg. 2011;77(5):659-665.

40. Zamboni WC. Liposomal, nanoparticle, and conjugated formulations of anticancer agents. Clin Cancer Res. 2005;11(23):8230-8234.

41. Yasuhiko T. Potential of drug delivery technology in tissue regeneration therapy. J Hard Tissue Biol. 2006;15(3):73-81.

42. Jin Y, Murakami N, Saito Y, Goto Y, Koishi K, Nonaka I. Expression of MyoD and myogenin in dystrophic mice, $\mathrm{mdx}$ and dy, during regeneration. Acta Neuropathol. 2000;99(6):619-627. 


\section{Supplementary materials \\ Detailed procedure}

C2C12 mouse adherent myoblasts (cell line obtained from National Cell Bank, Pasteur Institute of Iran) were grown in Dulbecco's Modified Eagle Medium (DMEM) supplemented with heat-inactivated $100 \%$ craniate bovine humor, $2 \mathrm{mM}$ amino acid, $0.5 \mathrm{~mL}$ penicillamine and streptomycin mixture, $0.5 \%$ anti-mycoplasm, and $25 \mathrm{mM}$ HEPES, $\mathrm{pH}$ 7.5. The cell line was maintained during a five-hitter dioxide atmosphere at $37^{\circ} \mathrm{C}$ and cell viability was assessed by an MTT (3-[4,5-Dimethylthiazol-2-yl]-2,5-diphenyltetrazolium bromide) assay. To induce myogenic differentiation, once the eightieth cell confluence was earned, the medium containing $100 \%$ craniate calf \{serum|blood humor|liquid body substance|bodily fluid|body fluid|humor|humor\} was substituted with one hundred and twenty fifth craniate calf serum. (Approximately 40,000 cells were exposed to each dose for at least three times).

The cells' growth was observed at critical time intervals, ie, at the undifferentiated stage and at the first and second days of exposure to different doses of nano-conjugate $(100,200$, and $400 \mathrm{nM}$ ), with $570 \mathrm{~nm}$ optical density observations.

\section{Results}

After 24 hours of exposure, at all concentrations, a nonsignificant increase in cell proliferations was observed, but surprisingly a significant $P<0.05$ cell proliferation enhancement was obtained at the high dose of $400 \mathrm{nM}$. The findings support in vivo pathophysiological observations.
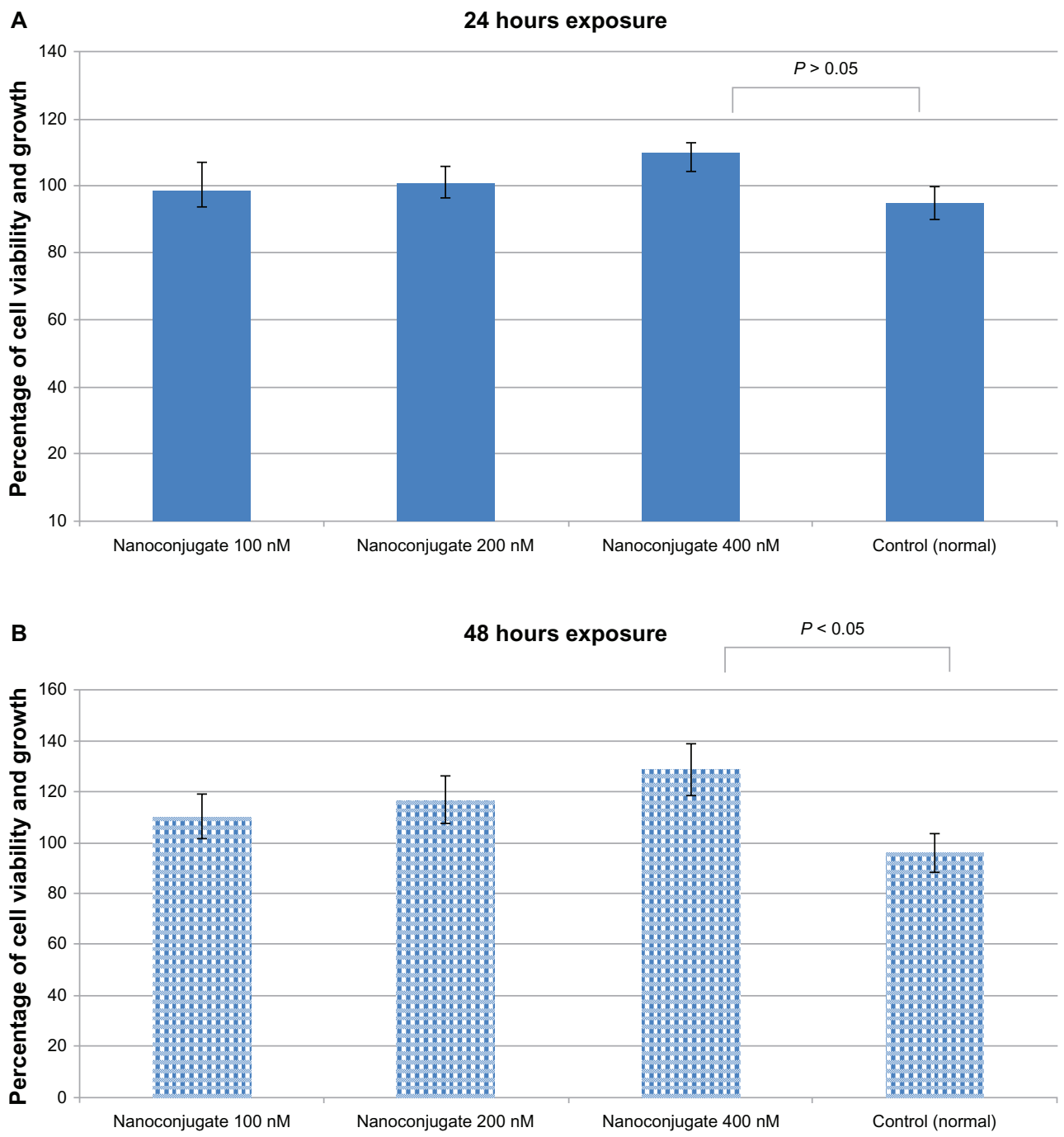

Figure SI Effects of nanolipodendrosome-loaded glatiramer acetate and MyoD on C2CI2 (mouse myoblast cell line) after 24 (A) and 48 (B) hours of exposure. Abbreviation: MyoD, myogenic differentiation I. 


\section{Publish your work in this journal}

The International Journal of Nanomedicine is an international, peerreviewed journal focusing on the application of nanotechnology in diagnostics, therapeutics, and drug delivery systems throughout the biomedical field. This journal is indexed on PubMed Central, MedLine, CAS, SciSearch $\AA$, Current Contents ${ }^{\circledR} /$ Clinical Medicine,

Journal Citation Reports/Science Edition, EMBase, Scopus and the Elsevier Bibliographic databases. The manuscript management system is completely online and includes a very quick and fair peer-review system, which is all easy to use. Visit http://www.dovepress.com/ testimonials.php to read real quotes from published authors.

Submit your manuscript here: http://www.dovepress.com/international-journal-of-nanomedicine-journal 